\title{
MGMT Promoter Methylation Is a Strong Prognostic Biomarker for Benefit from Dose-Intensified Temozolomide Rechallenge in Progressive Glioblastoma: The DIRECTOR Trial
}

Weller, Michael ; Tabatabai, G ; Kästner, B ; Felsberg, J ; Steinbach, J P ; Wick, A ; Schnell, O ; Hau, $\mathrm{P}$; Herrlinger, U ; Sabel, M C ; Wirsching, H G ; Ketter, R ; Bähr, O ; Platten, M ; Tonn, J C ; Schlegel, U ; Marosi, C ; Goldbrunner, R ; Stupp, R ; Homicsko, K ; Pichler, J ; Nikkhah, G ; Meixensberger, J ; Vajkoczy, P ; Kollias, S ; Hüsing, J ; Reifenberger, G ; Wick, W

\begin{abstract}
PURPOSE Rechallenge with temozolomide (TMZ) at first progression of glioblastoma after temozolomide chemoradiotherapy $(\mathrm{TMZ} / \mathrm{RT} \rightarrow \mathrm{TMZ})$ has been studied in retrospective and single-arm prospective studies, applying temozolomide continuously or using $7 / 14$ or $21 / 28$ days schedules. The DIRECTOR trial sought to show superiority of the $7 / 14$ regimen. PATIENTS AND METHODS Patients with glioblastoma at first progression after $\mathrm{TMZ} / \mathrm{RT} \rightarrow \mathrm{TMZ}$ and at least two maintenance temozolomide cycles were randomized to Arm A [one week on $(120 \mathrm{mg} / \mathrm{m}(2)$ per day)/one week off] or Arm B [3 weeks on (80 mg/m(2) per day)/one week off]. The primary endpoint was median time-to-treatment failure (TTF) defined as progression, premature temozolomide discontinuation for toxicity, or death from any cause. $\mathrm{O}(6)$-methylguanine DNA methyltransferase (MGMT) promoter methylation was prospectively assessed by methylation-specific PCR. RESULTS Because of withdrawal of support, the trial was prematurely closed to accrual after 105 patients. There was a similar outcome in both arms for median TTF [A: 1.8 months; $95 \%$ confidence intervals (CI), 1.8-3.2 vs. B: 2.0 months; 95\% CI, 1.8-3.5] and overall survival [A: 9.8 months (95\% CI, 6.7-13.0) vs. B: 10.6 months (95\% CI, 8.1-11.6)]. Median TTF in patients with MGMT-methylated tumors was 3.2 months (95\% CI, 1.8-7.4) versus 1.8 months (95\% CI, 1.8-2) in MGMT-unmethylated glioblastoma. Progression-free survival rates at 6 months (PFS-6) were 39.7\% with versus $6.9 \%$ without MGMT promoter methylation. CONCLUSIONS Temozolomide rechallenge is a treatment option for MGMT promoter-methylated recurrent glioblastoma. Alternative strategies need to be considered for patients with progressive glioblastoma without MGMT promoter methylation. Clin Cancer Res; 1-8. (O2015 AACR.
\end{abstract}

DOI: https://doi.org/10.1158/1078-0432.CCR-14-2737

Posted at the Zurich Open Repository and Archive, University of Zurich ZORA URL: https://doi.org/10.5167/uzh-110465

Journal Article

Accepted Version

Originally published at:

Weller, Michael; Tabatabai, G; Kästner, B; Felsberg, J; Steinbach, J P; Wick, A; Schnell, O; Hau, P; Herrlinger, U; Sabel, M C; Wirsching, H G; Ketter, R; Bähr, O; Platten, M; Tonn, J C; Schlegel, U; Marosi, C; Goldbrunner, R; Stupp, R; Homicsko, K; Pichler, J; Nikkhah, G; Meixensberger, J; Vajkoczy, P; Kollias, S; Hüsing, J; Reifenberger, G; Wick, W (2015). MGMT Promoter Methylation Is a 
Strong Prognostic Biomarker for Benefit from Dose-Intensified Temozolomide Rechallenge in Progressive Glioblastoma: The DIRECTOR Trial. Clinical Cancer Research, 21(9):2057-2064.

DOI: https://doi.org/10.1158/1078-0432.CCR-14-2737 
MGMT promoter methylation is a strong prognostic biomarker for benefit from dose-intensified temozolomide rechallenge in progressive glioblastoma: the DIRECTOR trial

Michael Weller ${ }^{1+}$, Ghazaleh Tabatabai ${ }^{1+}$, Bärbel Kästner ${ }^{2}$, Jörg Felsberg ${ }^{3}$, Joachim P. Steinbach ${ }^{4}$, Antje Wick ${ }^{5}$, Oliver Schnell ${ }^{6}$, Peter Hau ${ }^{7}$, Ulrich Herrlinger ${ }^{8}$, Michael C. Sabel $^{9}$, Hans-Georg Wirsching ${ }^{1}$, Ralf Ketter ${ }^{10}$, Oliver Bähr ${ }^{4}$, Michael Platten ${ }^{5}$, Jörg C. Tonn $^{6}$, Uwe Schlegel ${ }^{11}$, Christine Marosi ${ }^{12}$, Roland Goldbrunner ${ }^{13}$, Roger Stupp ${ }^{14}$, Krisztian Homicsko ${ }^{14}$, Josef Pichler ${ }^{15}$, Guido Nikkhah ${ }^{16}$, Jürgen Meixensberger ${ }^{17}$, Peter Vajkoczy ${ }^{18}$, Spyros Kollias ${ }^{19}$, Johannes Hüsing ${ }^{2}$, Guido Reifenberger ${ }^{3 \#}$, Wolfgang Wick ${ }^{5 \#}$, for the DIRECTOR Study Group

Departments of ${ }^{1}$ Neurology and ${ }^{19}$ Neuroradiology, University Hospital Zurich, Zurich, Switzerland; ${ }^{2}$ Clinical Trial Center Heidelberg, University Hospital Heidelberg, Heidelberg, Germany; ${ }^{3}$ Department of Neuropathology, Heinrich Heine University Düsseldorf, German Cancer Consortium (DKTK), German Cancer Research Center (DKFZ), Heidelberg, Germany; ${ }^{4} \mathrm{Dr}$. Senckenberg Institute for Neuro-Oncology, University Hospital Frankfurt, Frankfurt, Germany; ${ }^{5}$ Department of Neurology, Heidelberg University Medical Center; National Center for Tumor Diseases Heidelberg, German Cancer Consortium (DKTK), German Cancer Research Center (DKFZ), Heidelberg, Germany; ${ }^{6}$ Department of Neurosurgery, Ludwig Maximilian University of Munich, Munich, Germany, ${ }^{7}$ Department of Neurology and Wilhelm Sander-NeuroOncology Unit, University Hospital Regensburg, Regensburg, Germany; ${ }^{8}$ Division of Clinical Neuro-Oncology, Department of Neurology, University of Bonn Medical Center, Bonn, Germany; ${ }^{9}$ Department of Neurosurgery, Heinrich Heine University Düsseldorf, Düsseldorf, Germany; ${ }^{10}$ Department of Neurosurgery, 
Saarland University, Homburg, Germany; ${ }^{11}$ Department of Neurology, University Hospital Bochum, Bochum, Germany; ${ }^{12}$ Department of Oncology, Medical University Vienna, Vienna, Austria; ${ }^{13}$ Department of Neurosurgery, University Hospital Cologne, Cologne, Germany; ${ }^{14}$ Department of Neurosciences, Centre Hospitalier Universitaire Vaudois, Lausanne, Switzerland; ${ }^{15}$ Department of Oncology, Hospital Linz, Austria, ${ }^{16}$ Department of Neurosurgery, University Hospital Freiburg, Germany; ${ }^{17}$ Department of Neurosurgery, University Hospital Leipzig, Germany ${ }^{18}$ Department of Neurosurgery, University Hospital Berlin Charité, Germany

${ }^{+} \mathrm{MW}$ and GT share first authorship, "GR and WW share senior authorship.

\section{Running head}

DIRECTOR trial for recurrent glioblastoma

\section{Key words}

dose-intensified temozolomide, recurrent glioblastoma

\section{Financial support}

The DIRECTOR trial was supported by a grant from MSD (formerly Schering Plough) and a Matching Funds grant from the University Hospital Zurich, Switzerland.

\section{Corresponding author}

Michael Weller, MD, Department of Neurology, University Hospital Zurich, Zurich, Frauenklinikstrasse 26, 8091 Zurich, Switzerland, Phone: +41-44-255-5500, Fax: +41-44-255-4507, E-mail: michael.weller@usz.ch 
Trial registration ID

NCT00941460

\section{Potential conflict of interest}

J.S. and U.H. have received honoraria from Medac, G.T., M.W. and J.P. have received honoraria from MSD, J.T., M.W. and G.R. have received honoraria from Merck Serono, P.H. has provided expert testimony to Medac, W.W. has participated in a speaker's bureau for MSD, W.W., M.W. and J.P. have received research funding from MSD, M.W. has received research funding from Merck Serono, W.W. has received research funding from Boehringer, R.S. and M.W. have a consultant relationship with MSD, J.T. and M.W. have a consultant relationship with Merck Serono.

Word count 3689

Figures 2

Tables 4 


\section{Statement of clinical relevance}

The prospective randomized DIRECTOR trial assessed the efficacy and tolerability of two different regimens of rechallenge with intensified temozolomide (TMZ) at first progression of glioblastoma after temozolomide chemoradiotherapy (TMZ/RT $\rightarrow T M Z)$. Efficacy was similar in both arms, but depended strongly on MGMT promoter methylation status. TMZ rechallenge should no longer be considered for patients with tumors lacking MGMT promoter methylation, but is an appropriate option for patients with glioblastoma harboring MGMT promoter methylation at first relapse. 


\section{Abstract}

\section{Purpose}

Rechallenge with temozolomide (TMZ) at first progression of glioblastoma after temozolomide chemoradiotherapy $(T M Z / R T \rightarrow T M Z)$ has been studied in retrospective and single-arm prospective studies, applying $T M Z$ continuously or using $7 / 14$ or $21 / 28$ days schedules. The DIRECTOR trial sought to show superiority of the $7 / 14$ regimen.

\section{Patients \& Methods}

Patients with glioblastoma at first progression after TMZ/RT $\rightarrow T M Z$ and at least 2 maintenance TMZ cycles were randomized to Arm A (one week on $\left(120 \mathrm{mg} / \mathrm{m}^{2}\right.$ per day) / one week off) or Arm B (three weeks on ( $80 \mathrm{mg} / \mathrm{m}^{2}$ per day) / one week off). The primary end point was median time to treatment failure (TTF) defined as progression, premature TMZ discontinuation for toxicity, or death from any cause. $\mathrm{O}^{6}$ methylguanine DNA methyltransferase (MGMT) promoter methylation was prospectively assessed by methylation-specific PCR.

\section{Results}

Because of withdrawal of support, the trial was prematurely closed to accrual after 105 patients. There was a similar outcome in both arms for median TTF (A: 1.8 months [95\% Cl 1.8-3.2] versus $\mathrm{B}: 2.0$ months [95\% $\mathrm{Cl} 1.8-3.5])$ and overall survival (OS) (A: 9.8 months [95\% Cl 6.7-13.0] versus $\mathrm{B}: 10.6$ months [95\% $\mathrm{Cl}$ 8.1-11.6]). Median TTF in patients with MGMT-methylated tumors was 3.2 months [95\% CI 1.87.4] versus 1.8 months [95\% Cl 1.8-2] in MGMT-unmethylated glioblastoma. Progression-free survival rates at six months (PFS-6) were $39.7 \%$ with versus $6.9 \%$ without MGMT promoter methylation.

\section{Conclusions}


TMZ rechallenge is a treatment option for MGMT promoter-methylated recurrent glioblastoma. Alternative strategies need to be considered for patients with progressive glioblastoma without MGMT promoter methylation.

\section{Introduction}

The standard of care for newly diagnosed glioblastoma, with an incidence of more than $3 / 100,000$ the most common primary malignant brain tumor, includes resection or biopsy as feasible, involved field radiotherapy, and concomitant and adjuvant temozolomide (TMZ/RT $\rightarrow T M Z)$ (1). While anti-angiogenic agents such as the antibody to vascular endothelial growth factor, bevacizumab, or the integrin inhibitor cilengitide failed to prolong overall survival (2-4), the novel approach of tumortreating fields provided a survival advantage and may be incorporated into the future first-line treatment (5).

Standards of care at progression are less well defined (6): Depending on approval status, individual patient and tumor factors, and local preference, the most commonly used systemic therapeutic approaches include nitrosoureas such as lomustine (CCNU) which has become the standard of care in randomized clinical trials for recurrent glioblastoma $(7,8)$, temozolomide rechallenge using various regimens (912), and bevacizumab $(13,14)$. The need for prospective assessment of TMZ rechallenge after systematic recognition of pseudoprogression as a potential confounder of second-line treatments $(15,16)$ and the controversy regarding the optimal dosing of TMZ for patients with recurrent glioblastoma after failure of first-line $\mathrm{TMZ} / \mathrm{RT} \rightarrow \mathrm{TMZ}$ led to the design of the DIRECTOR (Dose-Intensified Rechallenge with Temozolomide, One Week on One Week Off versus Three Weeks on One Week 
Off in Patients with Progressive or Recurrent Glioblastoma) trial, which sought to explore the activity of two widely used regimens of dose-intense TMZ for recurrent glioblastoma, one week on / one week off (7/14) (9) versus three weeks on / one week off (10).

\section{Patients and Methods}

\section{Study design}

DIRECTOR (NCT 00941460) was designed as a prospective, open-label, randomized, 2-arm trial of two competing TMZ dosing regimens for patients with glioblastoma at first relapse or progression. The primary objective was to show the superiority of Arm A (one week on / one week off) over Arm B (three weeks on / one week off), the primary endpoint being time to treatment failure (TTF). Major inclusion criteria were: progressive or recurrent glioblastoma documented by MRI no earlier than 180 days after first surgery for glioblastoma and no earlier than 90 days after completion of radiotherapy (patients with progression outside the radiation field were also not allowed to be entered into the trial unless these time frames were respected); histological diagnosis of glioblastoma; tissue available for the determination of $\mathrm{O}^{6}$-methylguanine DNA methyltransferase (MGMT) promoter methylation in the primary or in the recurrent tumor; prior treatment with TMZ/RT and at least two cycles of maintenance TMZ (5/28); informed consent; age 18-80 years; Karnofsky performance score $\geq 50 \%$; absolute neutrophil counts $>1,500 / \mu \mathrm{l}$; platelet counts $>100,000 / \mu$; hemoglobin $>10 \mathrm{~g} / \mathrm{dl}$; serum creatinin $<1.5$-fold upper normal range; ASAT or ALAT < 3-fold upper normal range unless attributed to anticonvulsants; alkaline phosphatase $<3$-fold upper normal range; women with 
childbearing potential must have a negative serum pregnancy test $\leq 14$ days prior to study enrollment. Obligatory MGMT testing of the recurrent tumor as opposed to the primary tumor tissue was initially required, but no longer requested when it became clear that the result of the MGMT status determination rarely changes in the course of disease (17). All patients gave written informed consent, and the study was approved by the local ethical committees and competent authorities. The trial was prematurely closed for withdrawal of support after the merger of Schering Plough (Kenilworth, NJ) with Merck, Sharp \& Dohme (Whitehouse Station, NJ). Databank closure was on June 30, 2013.

Central pathology review, DNA extraction and MGMT promoter methylation analysis All tissue samples from primary or recurrent tumor were confirmed by central pathology review (G.R.) to represent glioblastoma according to the World Health Organisation (WHO) classification of tumors of the central nervous system (18). Tumor DNA was extracted from formalin-fixed and paraffin-embedded tissue samples using the Qiagen blood and tissue DNA extraction kit (Qiagen, Hilden, Germany). Each tumor sample used for DNA extraction was histologically verified to contain vital glioblastoma tissue with an estimated tumor cell content $\geq 80 \%$. The MGMT promoter methylation status was determined by methylation-specific PCR (MSP) and evaluated as reported (19). This MSP assays had been used in several previous studies (20-22) and was proven to show high concordance with results obtained by the MSP assay of MDxHealth S.A. (Herstal, Belgium) (22) and DNA pyrosequencing (17). 


\section{Study Treatment}

Patients were allocated either to the one week on / one week off regimen (7/14, Arm A) or to the three weeks on / one week off regimen (21/28, Arm B) of dose-intensified TMZ using a treatment allocation algorithm (23) with a probability of a minimizing allocation set at 0.9 . Arm A patients were treated at an initial dose of $120 \mathrm{mg} / \mathrm{m}^{2}$ unless there had been grade III or IV myelotoxicity with conventional TMZ (5/28) previously. These patients were started at $90 \mathrm{mg} / \mathrm{m}^{2} . \mathrm{TMZ}$ was given orally on days 1-7 and 15-21. Arm B patients started with an initial dose of $80 \mathrm{mg} / \mathrm{m}^{2}$ unless there had been significant myelotoxicity with conventional TMZ (5/28) previously. These patients started at $60 \mathrm{mg} / \mathrm{m}^{2}$. TMZ was given orally on days $1-21$. A treatment cycle was defined as two completed weeks of TMZ within four weeks in Arm A and as three weeks of continuous TMZ within four weeks in Arm B. Dose modifications were foreseen according to hematological parameters as outlined in Supplementary Table 1.

\section{Assessments and endpoints}

Patients were to be seen weekly during cycle 1 and monthly thereafter for general evaluation and blood tests. Toxicity was evaluated using the Common Terminology Criteria for Adverse Events (CTCAE v3.0). Cognitive function was assessed by MiniMental State Examination (MMSE) in 4-weekly intervals. Quality of life was monitored by EORTC QLQ-C30 and QLQ-BN20 in 8-weekly intervals. Disease status was monitored by MRI in 8-weekly intervals and assessed using Macdonald criteria as prespecified in the protocol (24). The primary endpoint, TTF, was calculated from randomization to any of the following: progressive disease defined by Macdonald criteria (24), death for any reason, or toxicity leading to discontinuation of study 
treatment for any reason. Secondary endpoints included progression-free survival (PFS) calculated as the time from randomization to the first documented evidence of progression of disease, survival from randomization, and efficacy parameters in subgroups defined by MGMT status. Radiological progression was evaluated at each center and also centrally verified post-hoc (blindly to previous results).

\section{Statistical analyses}

The targeted sample size was 83 patients per arm, and no interim analysis was planned. This size would have allowed for a detection of an improvement in median TTF from 18.2 weeks for Arm B to 29.2 weeks for Arm A (hazard ratio 0.63) $(10,25)$. Based on these assumptions, there was approximately $80 \%$ power to detect the stated difference in TTF between the two treatment arms for a two-sided level of 0.05. Treatment arms were compared using a permutation test (26) with 9999 replicates in the Cox proportional hazard model with the same parameters as explanatory variables used for the treatment allocation algorithm (MGMT promoter methylation status, $>2$ months since previous TMZ treatment, age at least 50 years, KPS $50-60,70-80$ or $90-100$ ) along with the variable for treatment. Since $p$ values from permutation tests were sufficiently close to those based on partial likelihoods as routinely used in parameter estimation in the Cox model, the latter were used for all subgroup analyses. Secondary analyses with respect to time-to-event variables were done using Cox proportional hazards models when considering multiple explanatory variables. Log-rank or bootstrap tests to compare median times and parametric tests with standard error approximation were used for univariate tests, especially when comparing rates at fixed time points. With respect to categorical variables, we used Fisher's exact test or logistic regression, and with respect to continuous variables linear regression models. Specifically, quality of life was analyzed using a linear 
mixed regression model with patient as random effect. All $p$ values, statistical tests and confidence intervals beyond the analysis of the primary criterion were not corrected for multiplicity and are to be interpreted as exploratory.

\section{Results}

\section{Patient characteristics}

105 patients were randomized at 16 sites from 9/2009 to 6/2012. Table 1 summarizes patient characteristics per treatment arm. Arms A and B were overall well balanced. More patients in Arm B had surgery for recurrent disease whereas more patients in Arm A had steroids at study entry. At the time of databank closure (30 June 2013), 87 deaths were documented, 84 were attributed to tumor progression, 3 documented with unknown course. No patient was still on study treatment. Four patients had not reached the primary endpoint of TTF (Figure 1).

\section{Safety and tolerability}

All adverse events were categorized by system organ class and graded according to CTCAE. There was no relevant difference between both arms regarding the frequency and severity of adverse events in the hematological system. Profound lymphopenia was the most common hematological toxicity, 19\% in Arm A and $29 \%$ in Arm B (Supplementary Table 1). Severe infections, however, were rare. Nonhematalogical adverse events, e.g., disorders of the gastrointestinal system, nervous system, metabolism, respiratory system, skin, cardiovascular system or musculoskeletal system occurred at similar rates in both treatment arms and were overall infrequent. 


\section{Outcome by treatment and MGMT status}

All clinical outcome parameters were comparable in Arms A and B (Figure 2, Table 2). Median TTF was below 2 months whereas median OS from first intake of study drug was in the range of 10 months. The $p$ value from the permutation test $(p=0.488)$ was close enough to the $p$ value using partial likelihood from the Cox model $(p=0.485)$ to justify taking the latter one for all other analyses. There were 2 CR $(4 \%)$ and 2 PR (4\%) in Arm A and 4 CR (8\%) and 4 PR (8\%) in Arm B by local assessment $(p=0.68)$ in response to the study treatment. The median duration of the $6 \mathrm{CR}$ was 4.5 months $(95 \% \mathrm{Cl} 1.8-11.0)$. The median duration of the $6 \mathrm{PR}$ was 3 months $(95 \% \mathrm{Cl} 1.8-13.6)$. TTF was diagnosed because of PD in all but three patients, confirming that tolerability was good. One patient developed wound infection at day 26, necessitating TMZ discontinuation, 2 patients died without documented PD. Age was not prognostic. As required per protocol MGMT status from primary or recurrent tumor was available for all patients. MGMT promoter methylation was strongly associated with superior TTF and all other outcome parameters (Figure 2, Table 3). The TTF difference between patients with versus without MGMT promoter methylation was more prominent in Arm B than in Arm A (Supplementary table 2). Overall survival from initial histological diagnosis of glioblastoma was 25.4 months $(95 \% \mathrm{Cl} 17.8-32.3)$ in Arm A and 22.7 months $(95 \%$

Cl 18.5-27.2) in Arm B. This shows that patients enrolled into randomized trials for recurrent glioblastoma represent a selected population.

\section{Central radiology review}

Serial MRI of 85 patients were available for post-hoc central review of progression. All these patients had measurable disease at baseline. The time point of progression 
was centrally confirmed in 81 patients. It was antedated 1 scan in 2 patients and not confirmed in 2 patients; 0 of $1 \mathrm{CR}$ and 2 of 3 PR were confirmed. Insufficient scans were provided for the other 12 patients considered objective responders locally.

\section{Outcome by preexposure to TMZ}

We also separated the patient populations by intensity and interval of preexposure to TMZ. Administration of more than 6 cycles of maintenance TMZ is uncommon in Europe (Table 1). To this end, we compared patients with intervals below $(n=40)$ or above 2 months $(n=65)$ since their last TMZ intake as specified in the study protocol. Four of $6 \mathrm{CR}$ and all 6 PR were noted in the latter group. Further, there was significantly improved outcome in patients with a longer delay since the last administration of $\mathrm{TMZ}$, more prominent in Arm A than in Arm B and largely confined to patients with MGMT promoter methylation (Supplementary table 3).

\section{MMSE and quality of life}

Serial assessments of MMSE and quality of life using EORTC QLQ-C30 and QLQBN20 were grouped into (i) pre-treatment, (ii) during study treatment and (iii) after study treatment assessments. For the latter two time intervals carrying multiple measures, we determined patient-wise minimum, median and maximum scores. The MMSE as a surrogate measure of cognitive function remained stable during treatment and did not exhibit a decline after the end of study treatment as long as data were captured (Supplementary Figure 1, Supplementary table 4). There was relatively little difference in quality of life assessed by QLQ-C30 and QLQ-BN20 when compared after the first 90 days of study treatment (Supplementary table 5). Treatment-by-time interaction indicated that quality of life developments were somewhat more favorable in Arm B, with significant differences for pain 
(Supplementary table 6). Although most scales are deteriorating over time (positive slope terms in either arm), the lack of major decline over time may result from the low number of assessments after the end of study treatment (Supplementary Table 7).

\section{Multivariate modeling of outcome}

Cox proportional hazards modeling for TTF revealed MGMT promoter methylation status and time interval from last TMZ exposure as independent prognostic factors whereas no such role was identified for age, KPS, surgery for recurrent tumor prior to enrolment (Table 4). Steroid administration at study entry, body surface area, body weight, red or white blood cell or lymphocyte counts, hemoglobin or hematocrit at study entry were not prognostic for TTF (data not shown). Similar results were obtained when Cox proportional hazards modeling was applied to PFS whereas only MGMT status was prognostic for survival from first study drug administration (data not shown).

\section{Discussion}

Standards of care in recurrent glioblastoma are not well defined. This definitive report of the phase II randomized DIRECTOR trial indicates that TMZ rechallenge is a valid treatment option for patients with recurrent glioblastoma with, but not without, MGMT promoter methylation.

The optimal dosing of TMZ in glioblastoma became a dominant topic in the first decade of this century in Neuro-Oncology, in part reflecting the lack of promising alternative drugs, in part also reflecting the consideration that TMZ activity is critically limited by chemoresistance afforded by $\operatorname{MGMT}(27,28)$. MGMT promoter methylation 
is observed in $30-40 \%$ of glioblastomas, presumably resulting in decreased MGMT gene expression in the MGMT promoter-methylated tumor cells, thereby rendering glioblastomas more sensitive to TMZ. However, a predictive role of MGMT promoter methylation for benefit from alkylating chemotherapy including TMZ has only been defined for glioblastoma whereas MGMT promoter methylation is prognostic for better outcome with either radiotherapy or chemotherapy in patients with anaplastic gliomas $(29,30)$. This difference in biological significance of MGMT promoter methylation is probably not related to grade of malignancy per se, but to the differential distribution of isocitrate dehydrogenase $(I D H)$ mutations among these tumors. MGMT promoter methylation associated with $I D H$ mutation and the gliomaassociated $\mathrm{CpG}$ island methylator phenotype (G-CIMP) does not have the same significance as MGMT promoter methylation on the wild-type IDH background of glioblastoma $(31,32)$.

Since TMZ depletes MGMT protein in peripheral blood mononuclear cells (33) and presumably glioblastoma cells, too, it was tempting to speculate that higher doses of TMZ given over a longer time frame would eventually deplete MGMT. Accordingly, it was assumed that specifically patients with glioblastomas lacking MGMT promoter methylation might benefit from dose-intense TMZ regimens. In addition and in parallel to DIRECTOR, two further trials explored the potential role of TMZ dose intensification in glioblastoma. For the newly diagnosed setting, the hypothesis that more TMZ might deplete MGMT and confer a survival benefit was falsified by the RTOG 0525 trial which confirmed the strong prognostic role of the MGMT status in TMZ-treated patients, but showed no difference between standard-dosed TMZ or a three weeks on / one week off regimen for 6-12 cycles in the maintenance phase, also not when the analysis was stratified for MGMT status (34). The BR12 trial analysed the same two regimens in comparison with procarbacine, CCNU and 
vincristine $(\mathrm{PCV})$ in recurrent malignant glioma and similarly observed no difference between the three arms (35). However, this trial had enrolled chemonaive patients with WHO grade III or IV gliomas which does not inform about the current situation in clinical practice where recurrent or progressive glioblastoma patients have commonly been pretreated with $T M Z / R T \rightarrow T M Z$.

The DIRECTOR trial reports a median TTF in the range of 2 months and yields overall no evidence that there are clinically relevant differences between the two dosing regimens, regarding either efficacy, safety or tolerability (Figure 2. Tables 2 and 3). Importantly, the dosing regimens were both confirmed to be feasible, given that PD was driving TTF in all, but one patient(s). The PFS- 6 rate of $21 \%$ is in the range of previously reported figures of $11-24 \%(11,12,36)$. In contrast to the RESCUE trial (11), we observed a better PFS in patients off TMZ for 2 months or more (Supplementary table 3). Of note, it is uncommon in Europe to give TMZ for more than 6 months (Table 1). These considerations indicate that some of the patients escalated to dose-intensified TMZ regimens early in the disease course in RESCUE as well as in our previous reports (37) were in fact suffering from pseudoprogression, artificially raising the PFS-6 rate. Increased awareness of pseudoprogression may thus explain an apparent decrease in PFS-6 rates with TMZ rechallenge in contemporary studies (12), and challenges all cross trial comparisons to older series. Moreover, differences in the PFS-6 figures for TMZ rechallenge - and probably CCNU, too - are likely to be related to the proportion of patients with tumors with MGMT promoter methylation in these studies, e.g., PFS-6 was $26 \%$ with versus $0 \%$ without MGMT promoter methylation in the control arm of the BELOB trial (38). The major limitations of the DIRECTOR trial are the relatively small sample size and the premature closure of the study which allows for less definitive conclusions. Yet, despite the lower than planned sample size and the premature trial closure, the 
likelyhood of a major difference in efficacy between the different TMZ schedules is very low.

In fact, the most important result of DIRECTOR is the strong prognostic role of the MGMT promoter methylation status in patients rechallenged with $\mathrm{TMZ}$ that has not previously been studied prospectively in an adequately sized patient population. In contrast, age and KPS were not prognostic, likely reflecting preselection of patients enrolled into randomized trials for recurrent as opposed to newly diagnosed glioblastoma enriching patients with a similar, relatively favorable outcome. MGMT status was centrally assessed and was available for all patients. Although there was only a moderate advantage in median TTF of 3.2 versus 1.8 months in patients with MGMT promoter-methylated versus unmethylated tumors, PFS-6 was increased 5.8fold, and OS at 12 months 2.4-fold (Figure 2, Table 3). Yet, given the absence of an inactive comparator or a placebo, it cannot be excluded that MGMT promoter methylation is merely prognostic. Thus, bevacizumab alone was associated with superior PFS at 6 months in patients with tumors with versus without MGMT promoter methylation in the BELOB trial, too (38), supporting a prognostic role of MGMT promoter methylation in recurrent glioblastoma. Randomization between $\mathrm{TMZ}$ and placebo and the demonstration of benefit from TMZ exclusively in patients with tumors with MGMT promoter methylation would be required for definitive confirmation, but is neither feasible nor ethical in patients with recurrent glioblastoma. The findings of the DIRECTOR trial have implications for current clinical practice. Based on DIRECTOR, TMZ rechallenge should no longer be considered for patients with tumors lacking MGMT promoter methylation, but remains a viable option for patients with MGMT promoter-methylated glioblastomas, notably after a drug-free interval of 2 months or more. Whether TMZ given at 5 out of 28 days would be as effective as dose-intense regimens in patients recurring after a drug-free interval, 
remains uncertain, but the $5 / 28$ regimen may be preferred in that setting because of better tolerability. More importantly, it may be speculated that a similarly profound prognostic effect of the MGMT status would have been seen, had the patients been treated with nitrosoureas instead of TMZ (38). If confirmed, this would call for MGMT testing of primary or recurrent tumor and stratification for all, notably smaller randomized recurrent glioblastoma trials carrying an alkylator control arm because imbalances in the distribution of patients with MGMT-unmethylated versus MGMTmethylated tumors could severely bias outcome. In conclusion, DIRECTOR supports stratified treatment algorithms based on MGMT promoter methylation status in recurrent glioblastoma and advocates an alkylator regimen, including dose-dense TMZ, as the most appropriate option for patients with glioblastoma harboring MGMT promoter methylation.

\section{Acknowledgement}

The following institutions (in alphabetical order) and investigators or study personnel participated in the trial: University Hospital Berlin Charité (P. Vajkoczy, M. Stoffels), University Hospital Bochum (U. Schlegel, T. Kowalski, A. Pox), University Hospital Bonn (U. Herrlinger, M. Stuplich, N. Schäfer, C. Landwehr), University Hospital Düsseldorf (J. Felsberg, G. Reifenberger, M. Sabel), University Hospital Frankfurt (J. Steinbach, O. Bähr, J. Hartan), University Hospital Freiburg (G. Nikkhah), University Hospital Heidelberg (W. Wick, A. Wick, M. Platten, D. Schemmer), University Hospital Homburg (R. Ketter), University Hospital Cologne (R. Goldbrunner, S. Grau, E. Cakmak), University Hospital Leipzig (J. Meixensberger), University Hospital Munich (J.C. Tonn, O. Schnell), University Hospital Regensburg (P. Hau, C. Wismeth, C. Reinert) in Germany, Hospital Linz (J. Pichler) and Medical University Vienna (C. Marosi) in Austria, and CHUV Lausanne (R. Stupp, A. Hottinger, K. 
Homicsko) and University Hospital Zurich (M. Weller, G. Tabatabai, H.G. Wirsching, V. Reichl) in Switzerland. The Clinical Coordination Center (KKS) in Heidelberg was responsible for data management, biometry, monitoring and data analysis (B.

Kaestner, J. Huesing, S. Luntz). The authors thank J. Schuth and S. Hecker (MSD, formerly Essex Germany) and B. Winograd, L. Hollis and M. Manzo (MSD, formerly Schering Plough) for their support in the early phase of this project and all patients and their families for participation in the trial.

\section{References}

1. Weller M, van den Bent M, Hopkins K, Tonn JC, Stupp R, Falini A, et al. EANO guideline for the diagnosis and treatment of anaplastic gliomas and glioblastoma. The Lancet Oncology. 2014;15:e395-e403.

2. Chinot OL, Wick W, Mason W, Henriksson R, Saran F, Nishikawa R, et al. Bevacizumab plus radiotherapy-temozolomide for newly diagnosed glioblastoma. The New England journal of medicine. 2014;370:709-22.

3. Gilbert MR, Dignam JJ, Armstrong TS, Wefel JS, Blumenthal DT, Vogelbaum MA, et al. A randomized trial of bevacizumab for newly diagnosed glioblastoma. The New England journal of medicine. 2014;370:699-708.

4. Stupp R, Hegi ME, Gorlia T, Erridge SC, Perry J, Hong YK, et al. Cilengitide combined with standard treatment for patients with newly diagnosed glioblastoma with methylated MGMT promoter (CENTRIC EORTC 26071-22072 study): a multicentre, randomised, open-label, phase 3 trial. The lancet oncology. $2014 ; 15: 1100-8$

5. Stupp R, Wong ET, Scott CB, Kirson ED, Palti Y, Taillibert S, et al. Interim analysis of the EF-14 trial: a prospective, multicenter trial of NovoTTF-100A together 
with temozolomide compared to temozolomide alone in patients with newly diagnosed GBM. Presented at: 19th Annual Meeting of the Society for NeuroOncology; November 13-16, 2014: Miami, FL. 2014.

6. Weller M, Cloughesy T, Perry JR, Wick W. Standards of care for treatment of recurrent glioblastoma--are we there yet? Neuro-oncology. 2013;15:4-27.

7. Wick W, Puduvalli VK, Chamberlain MC, van den Bent MJ, Carpentier AF, Cher LM, et al. Phase III study of enzastaurin compared with lomustine in the treatment of recurrent intracranial glioblastoma. Journal of clinical oncology : official journal of the American Society of Clinical Oncology. 2010;28:1168-74.

8. Batchelor TT, Mulholland P, Neyns B, Nabors LB, Campone M, Wick A, et al. Phase III randomized trial comparing the efficacy of cediranib as monotherapy, and in combination with lomustine, versus lomustine alone in patients with recurrent glioblastoma. Journal of clinical oncology : official journal of the American Society of Clinical Oncology. 2013;31:3212-8.

9. Wick W, Steinbach JP, Kuker WM, Dichgans J, Bamberg M, Weller M. One week on/one week off: a novel active regimen of temozolomide for recurrent glioblastoma. Neurology. 2004;62:2113-5.

10. Brandes AA, Tosoni A, Cavallo G, Bertorelle R, Gioia V, Franceschi E, et al. Temozolomide 3 weeks on and 1 week off as first-line therapy for recurrent glioblastoma: phase II study from gruppo italiano cooperativo di neuro-oncologia (GICNO). British journal of cancer. 2006;95:1155-60.

11. Perry JR, Belanger K, Mason WP, Fulton D, Kavan P, Easaw J, et al. Phase II trial of continuous dose-intense temozolomide in recurrent malignant glioma: RESCUE study. Journal of clinical oncology : official journal of the American Society of Clinical Oncology. 2010;28:2051-7. 
12. Norden AD, Lesser GJ, Drappatz J, Ligon KL, Hammond SN, Lee EQ, et al. Phase 2 study of dose-intense temozolomide in recurrent glioblastoma. Neurooncology. 2013;15:930-5.

13. Friedman HS, Prados MD, Wen PY, Mikkelsen T, Schiff D, Abrey LE, et al. Bevacizumab alone and in combination with irinotecan in recurrent glioblastoma. Journal of clinical oncology : official journal of the American Society of Clinical Oncology. 2009;27:4733-40.

14. Kreisl TN, Kim L, Moore K, Duic P, Royce C, Stroud I, et al. Phase II trial of single-agent bevacizumab followed by bevacizumab plus irinotecan at tumor progression in recurrent glioblastoma. Journal of clinical oncology : official journal of the American Society of Clinical Oncology. 2009;27:740-5.

15. Gerstner ER, McNamara MB, Norden AD, Lafrankie D, Wen PY. Effect of adding temozolomide to radiation therapy on the incidence of pseudo-progression. Journal of neuro-oncology. 2009;94:97-101.

16. Brandsma D, van den Bent MJ. Pseudoprogression and pseudoresponse in the treatment of gliomas. Current opinion in neurology. 2009;22:633-8.

17. Felsberg J, Thon N, Eigenbrod S, Hentschel B, Sabel MC, Westphal M, et al. Promoter methylation and expression of MGMT and the DNA mismatch repair genes MLH1, MSH2, MSH6 and PMS2 in paired primary and recurrent glioblastomas. International journal of cancer Journal international du cancer. 2011;129:659-70. 18. Louis DN, Ohgaki H, Wiestler OD, Cavenee WK, Burger PC, Jouvet A, et al. The 2007 WHO classification of tumours of the central nervous system. Acta neuropathologica. 2007;114:97-109.

19. Felsberg J, Rapp M, Loeser S, Fimmers R, Stummer W, Goeppert M, et al. Prognostic significance of molecular markers and extent of resection in primary 
glioblastoma patients. Clinical cancer research : an official journal of the American Association for Cancer Research. 2009;15:6683-93.

20. Weller M, Felsberg J, Hartmann C, Berger H, Steinbach JP, Schramm J, et al. Molecular predictors of progression-free and overall survival in patients with newly diagnosed glioblastoma: a prospective translational study of the German Glioma Network. Journal of clinical oncology : official journal of the American Society of Clinical Oncology. 2009;27:5743-50.

21. Reifenberger G, Hentschel B, Felsberg J, Schackert G, Simon M, Schnell O, et al. Predictive impact of MGMT promoter methylation in glioblastoma of the elderly. International journal of cancer Journal international du cancer. 2012;131:1342-50.

22. Wick W, Platten M, Meisner C, Felsberg J, Tabatabai G, Simon M, et al. Temozolomide chemotherapy alone versus radiotherapy alone for malignant astrocytoma in the elderly: the NOA-08 randomised, phase 3 trial. The lancet oncology. 2012;13:707-15.

23. Pocock SJ, Simon R. Sequential treatment assignment with balancing for prognostic factors in the controlled clinical trial. Biometrics. 1975;31:103-15.

24. Macdonald DR, Cascino TL, Schold SC, Jr., Cairncross JG. Response criteria for phase II studies of supratentorial malignant glioma. Journal of clinical oncology : official journal of the American Society of Clinical Oncology. 1990;8:1277-80.

25. Wick A, Felsberg J, Steinbach JP, Herrlinger U, Platten M, Blaschke B, et al. Efficacy and tolerability of temozolomide in an alternating weekly regimen in patients with recurrent glioma. Journal of clinical oncology : official journal of the American Society of Clinical Oncology. 2007;25:3357-61.

26. Hasegawa T, Tango T. Permutation test following covariate-adaptive randomization in randomized controlled trials. Journal of biopharmaceutical statistics. 2009;19:106-19. 
27. Hegi ME, Diserens AC, Gorlia T, Hamou MF, de Tribolet N, Weller M, et al. MGMT gene silencing and benefit from temozolomide in glioblastoma. The New England journal of medicine. 2005;352:997-1003.

28. Weller M, Stupp R, Reifenberger G, Brandes AA, van den Bent MJ, Wick W, et al. MGMT promoter methylation in malignant gliomas: ready for personalized medicine? Nature reviews Neurology. 2010;6:39-51.

29. Wick W, Hartmann C, Engel C, Stoffels M, Felsberg J, Stockhammer F, et al. NOA-04 randomized phase III trial of sequential radiochemotherapy of anaplastic glioma with procarbazine, lomustine, and vincristine or temozolomide. Journal of clinical oncology : official journal of the American Society of Clinical Oncology. $2009 ; 27: 5874-80$.

30. van den Bent MJ, Dubbink HJ, Sanson M, van der Lee-Haarloo CR, Hegi M, Jeuken JW, et al. MGMT promoter methylation is prognostic but not predictive for outcome to adjuvant PCV chemotherapy in anaplastic oligodendroglial tumors: a report from EORTC Brain Tumor Group Study 26951. Journal of clinical oncology : official journal of the American Society of Clinical Oncology. 2009;27:5881-6.

31. Bady P, Sciuscio D, Diserens AC, Bloch J, van den Bent MJ, Marosi C, et al. MGMT methylation analysis of glioblastoma on the Infinium methylation BeadChip identifies two distinct $\mathrm{CpG}$ regions associated with gene silencing and outcome, yielding a prediction model for comparisons across datasets, tumor grades, and CIMP-status. Acta neuropathologica. 2012;124:547-60.

32. Wick W, Meisner C, Hentschel B, Platten M, Schilling A, Wiestler B, et al. Prognostic or predictive value of MGMT promoter methylation in gliomas depends on IDH1 mutation. Neurology. 2013;81:1515-22. 
33. Tolcher AW, Gerson SL, Denis L, Geyer C, Hammond LA, Patnaik A, et al. Marked inactivation of O6-alkylguanine-DNA alkyltransferase activity with protracted temozolomide schedules. British journal of cancer. 2003;88:1004-11.

34. Gilbert MR, Wang M, Aldape KD, Stupp R, Hegi ME, Jaeckle KA, et al. Dosedense temozolomide for newly diagnosed glioblastoma: a randomized phase III clinical trial. Journal of clinical oncology : official journal of the American Society of Clinical Oncology. 2013;31:4085-91.

35. Brada M, Stenning S, Gabe R, Thompson LC, Levy D, Rampling R, et al. Temozolomide versus procarbazine, lomustine, and vincristine in recurrent highgrade glioma. Journal of clinical oncology : official journal of the American Society of Clinical Oncology. 2010;28:4601-8.

36. Han SJ, Rolston JD, Molinaro AM, Clarke JL, Prados MD, Chang SM, et al. Phase II trial of 7 days on/7 days off temozolmide for recurrent high-grade glioma. Neuro-oncology. 2014;16:1255-62.

37. Wick A, Pascher C, Wick W, Jauch T, Weller M, Bogdahn U, et al. Rechallenge with temozolomide in patients with recurrent gliomas. Journal of neurology. 2009;256:734-41.

38. Taal W, Oosterkamp HM, Walenkamp AM, Dubbink HJ, Beerepoot LV, Hanse MC, et al. Single-agent bevacizumab or lomustine versus a combination of bevacizumab plus lomustine in patients with recurrent glioblastoma (BELOB trial): a randomised controlled phase 2 trial. The lancet oncology. 2014;15:943-53. 
Table 1. Patient characteristics prior to enrolment

\begin{tabular}{|c|c|c|}
\hline & $\begin{array}{c}\text { Arm A } \\
7 / 7 \\
\mathrm{~N}=52 \\
\end{array}$ & $\begin{array}{c}\text { Arm B } \\
21 / 7 \\
\mathrm{~N}=53\end{array}$ \\
\hline \multicolumn{3}{|l|}{ Age at diagnosis } \\
\hline Median (years) & 58 & 56 \\
\hline Range (years) & $21-62$ & $37-59$ \\
\hline \multicolumn{3}{|l|}{ Gender } \\
\hline Male & $34(65 \%)$ & $35(66 \%)$ \\
\hline Female & $18(35 \%)$ & $18(34 \%)$ \\
\hline \multicolumn{3}{|l|}{ MGMT promoter } \\
\hline Methylated & $28(53.8 \%)$ & $31(58.5 \%)$ \\
\hline Unmethylated & $24(46.2 \%)$ & $22(41.5 \%)$ \\
\hline \multicolumn{3}{|l|}{ First-line therapy } \\
\hline TMZ/RT & $52(100.0 \%)$ & $53(100.0 \%)$ \\
\hline \multicolumn{3}{|l|}{ Number of maintenance TMZ cycles } \\
\hline No data & $1(1.9 \%)$ & $0(0 \%)$ \\
\hline$\leq 3$ & $9(17.3 \%)$ & $12(22.6 \%)$ \\
\hline $4-6$ & $32(61.5 \%)$ & $33(62.3 \%)$ \\
\hline 7 or more & $10(19.2 \%)$ & $8(15.1 \%)$ \\
\hline \multicolumn{3}{|l|}{ Time since last TMZ administration } \\
\hline$<2$ months & $20(38.5 \%)$ & $20(37.7 \%)$ \\
\hline$\geq 2$ months & $32(61.5 \%)$ & $33(62.3 \%)$ \\
\hline \multicolumn{3}{|l|}{ Survival } \\
\hline Median PFS (months, 95\% Cl) & $12.0(8.8-17.0)$ & $11.0(9.2-12.9)$ \\
\hline \multicolumn{3}{|l|}{ KPS at study entry } \\
\hline $90-100$ & $30(57.7 \%)$ & $30(56.6 \%)$ \\
\hline $70-80$ & $15(28.8 \%)$ & $16(30.2 \%)$ \\
\hline$<70$ & $7(13.5 \%)$ & $7(13.2 \%)$ \\
\hline \multicolumn{3}{|l|}{ Steroids at study entry } \\
\hline Yes & $16(30.8 \%)$ & $12(22.6 \%)$ \\
\hline No & $36(69.2 \%)$ & $41(77.4 \%)$ \\
\hline \multicolumn{3}{|l|}{ Surgery for recurrence } \\
\hline Yes & $29(55.8 \%)$ & $32(60.4 \%)$ \\
\hline No & $23(44.2 \%)$ & $21(39.6 \%)$ \\
\hline
\end{tabular}

Abbreviations: $\mathrm{Cl}$, confidence interval; KPS, Karnofsky performance score; MGMT, $\mathrm{O}^{6}$-methylguanine DNA methyltransferase; OS, overall survival; PFS, progressionfree survival; TMZ, temozolomide. 
Table 2. Outcome by treatment arm.

\begin{tabular}{|c|c|c|c|c|c|c|c|}
\hline & \multicolumn{3}{|c|}{ Arm A (7/14) } & \multicolumn{3}{|c|}{ Arm B (21/28) } & \\
\hline & Patients & Events & $\begin{array}{c}\text { Time in months } \\
(95 \% \mathrm{Cl})\end{array}$ & Patients & Events & $\begin{array}{c}\text { Time in months } \\
(95 \% \mathrm{Cl})\end{array}$ & $p$ \\
\hline Median TTF & 52 & 49 & $1.8[1.8 ; 3.2]$ & 53 & 49 & $1.95[1.84 ; 3.44]$ & 0.37 \\
\hline $\begin{array}{l}\text { Median survival from } \\
\text { first study drug } \\
\text { administration }\end{array}$ & 52 & 42 & $9.8[6.6 ; 13.0]$ & 53 & 45 & $10.6[8.1 ; 11.7]$ & 0.78 \\
\hline & & & $\begin{array}{l}\text { Rate in \% } \\
(95 \% \mathrm{Cl})\end{array}$ & & & $\begin{array}{c}\text { Rate in \% } \\
(95 \% \mathrm{Cl})\end{array}$ & \\
\hline
\end{tabular}

Abbreviations: $\mathrm{CI}$, confidence interval; PFS, progression-free survival; TTF, time to treatment failure. 
Table 3. Outcome by MGMT promoter methylation status.

\begin{tabular}{|c|c|c|c|c|c|c|c|}
\hline & \multicolumn{3}{|c|}{ MGMT-unmethylated glioblastoma } & \multicolumn{3}{|c|}{ MGMT-methylated glioblastoma } & \\
\hline & Patients & Events & $\begin{array}{c}\text { Time in months } \\
(95 \% \mathrm{Cl})\end{array}$ & Patients & Events & $\begin{array}{c}\text { Time in months } \\
(95 \% \mathrm{Cl})\end{array}$ & $p$ \\
\hline Median TTF & 59 & 56 & $1.8[1.8 ; 2.0]$ & 46 & 42 & $3.2[1.8 ; 7.3]$ & 0.0014 \\
\hline $\begin{array}{l}\text { Median survival } \\
\text { from first study } \\
\text { drug } \\
\text { administration }\end{array}$ & 59 & 50 & $7.9[6.3 ; 10.3]$ & 46 & 36 & $12.5[9.8 ; 17.4]$ & 0.0009 \\
\hline & & & $\begin{array}{l}\text { Rate in \% } \\
(95 \% \mathrm{Cl})\end{array}$ & & & $\begin{array}{l}\text { Rate in\% } \\
(95 \% \mathrm{Cl})\end{array}$ & \\
\hline PFS-6 & 58 & 54 & $6.9[2.2 ; 15.3]$ & 44 & 27 & $39.7[25.5 ; 53.5]$ & $<0.0001$ \\
\hline $\begin{array}{l}\text { Survival rate at } \\
12 \text { months from } \\
\text { first study drug } \\
\text { administration }\end{array}$ & 53 & 41 & $22.9[12.7 ; 34.9]$ & 41 & 19 & $54.1(37.8 ; 67.8)$ & 0.0013 \\
\hline
\end{tabular}

Abbreviations: $\mathrm{Cl}$, confidence interval; PFS, progression-free survival; TTF, time to treatment failure. 
Table 4. Multivariate analyses of predictors for inferior TTF.

\begin{tabular}{|l|c|c|}
\hline & $\begin{array}{c}\text { Hazard ratio } \\
\text { and } 95 \% \mathbf{~ C l}\end{array}$ & $\mathbf{p}$ \\
\hline Arm A versus Arm B & $1.16(0.76-1.76)$ & 0.485 \\
\hline Age at study entry 50+ versus 18-49 years & $1.27(0.76-2.20)$ & 0.381 \\
\hline Time interval since last TMZ: < versus $\geq 2$ months & $1.60(1.00-2.55)$ & $\mathbf{0 . 0 3 6}$ \\
\hline Salvage surgery: no versus yes & $1.02(0.65-1.57)$ & 0.945 \\
\hline KPS 50-60 versus 90-100 & $1.03(0.52-1.92)$ & 0.786 \\
KPS 70-80 versus 90-100 & $1.05(0.63-1.73)$ & 0.841 \\
\hline MGMT promoter: unmethylated versus methylated & $1.76(1.11-2.82)$ & $\mathbf{0 . 0 1 7}$ \\
\hline
\end{tabular}

${ }^{1}$ Hazard ratios as exponential function of parameter estimates and confidence interval. Estimates from a Cox model containing arm, treatment, age, time since last TMZ, salvage surgery: no versus yes, KPS, and MGMT promoter methylation status as explanatory variables. Other factors which are mentioned in the text, were included as additional variables in turn (one at a time). 
Figure Legends

Figure 1. CONSORT chart.

Figure 2. Clinical outcome. TTF (A) and OS (B) in Arm A (7/14) versus Arm B (21/28). TTF (C) and OS (D) in patients without versus with MGMT promoter methylation. 


\section{MGMT promoter methylation is a strong prognostic biomarker for benefit from dose-intensified temozolomide rechallenge in progressive glioblastoma: the DIRECTOR trial}

Michael Weller $^{1+}$, Ghazaleh Tabatabai ${ }^{1+}$, Bärbel Kästner ${ }^{2}$, Jörg Felsberg ${ }^{3}$, Joachim P. Steinbach ${ }^{4}$, Antje Wick $^{5}$, Oliver Schnell ${ }^{6}$, Peter $\mathrm{Hau}^{7}$, Ulrich Herrlinger ${ }^{8}$, Michael C. Sabel $^{9}$, Hans-Georg Wirsching ${ }^{1}$, Ralf Ketter ${ }^{10}$, Oliver Bähr ${ }^{4}$, Michael Platten ${ }^{5}$, Jörg C. Tonn $^{6}$, Uwe Schlegel ${ }^{11}$, Christine Marosi ${ }^{12}$, Roland Goldbrunner ${ }^{13}$, Roger Stupp ${ }^{14}$, Krisztian Homicsko ${ }^{14}$, Josef Pichler ${ }^{15}$, Guido Nikkhah ${ }^{16}$, Jürgen Meixensberger ${ }^{17}$, Peter Vajkoczy ${ }^{18}$, Spyros Kollias ${ }^{19}$, Johannes Hüsing ${ }^{2}$, Guido Reifenberger ${ }^{3 \#}$, Wolfgang Wick ${ }^{5 \#}$, for the DIRECTOR Study Group

Departments of ${ }^{1}$ Neurology and ${ }^{19}$ Neuroradiology, University Hospital Zurich, Zurich, Switzerland; ${ }^{2}$ Clinical Trial Center Heidelberg, University Hospital Heidelberg, Heidelberg, Germany; ${ }^{3}$ Department of Neuropathology, Heinrich Heine University Düsseldorf, German Cancer Consortium (DKTK), German Cancer Research Center (DKFZ), Heidelberg, Germany; ${ }^{4}$ Dr. Senckenberg Institute for Neuro-Oncology, University Hospital Frankfurt, Frankfurt, Germany; ${ }^{5}$ Department of Neurology, Heidelberg University Medical Center; National Center for Tumor Diseases Heidelberg, German Cancer Consortium (DKTK), German Cancer Research Center (DKFZ), Heidelberg, Germany; ${ }^{6}$ Department of Neurosurgery, Ludwig Maximilian University of Munich, Munich, Germany, ${ }^{7}$ Department of Neurology and Wilhelm Sander-NeuroOncology Unit, University Hospital Regensburg, Regensburg, Germany; ${ }^{8}$ Division of Clinical Neuro-Oncology, Department of Neurology, University of Bonn Medical Center, Bonn, Germany; ${ }^{9}$ Department of Neurosurgery, Heinrich Heine University Düsseldorf, Düsseldorf, Germany; ${ }^{10}$ Department of Neurosurgery, 
Saarland University, Homburg, Germany; ${ }^{11}$ Department of Neurology, University Hospital Bochum, Bochum, Germany; ${ }^{12}$ Department of Oncology, Medical University Vienna, Vienna, Austria; ${ }^{13}$ Department of Neurosurgery, University Hospital Cologne, Cologne, Germany; ${ }^{14}$ Department of Neurosciences, Centre Hospitalier Universitaire Vaudois, Lausanne, Switzerland; ${ }^{15}$ Department of Oncology, Hospital Linz, Austria, ${ }^{16}$ Department of Neurosurgery, University Hospital Freiburg, Germany; ${ }^{17}$ Department of Neurosurgery, University Hospital Leipzig, Germany ${ }^{18}$ Department of Neurosurgery, University Hospital Berlin Charité, Germany ${ }^{+} \mathrm{MW}$ and GT share first authorship, ${ }^{\#} \mathrm{GR}$ and WW share senior authorship.

\section{Running head}

DIRECTOR trial for recurrent glioblastoma 
Supplementary Figure 1. MMSE assessment at study entry, during treatment, and at follow-up. Arm a is depicted in green, Arm B in red.

Quantile $=\max$

Study stage

Baseline

\begin{tabular}{l|l} 
Treatment period & Follow-up period
\end{tabular}

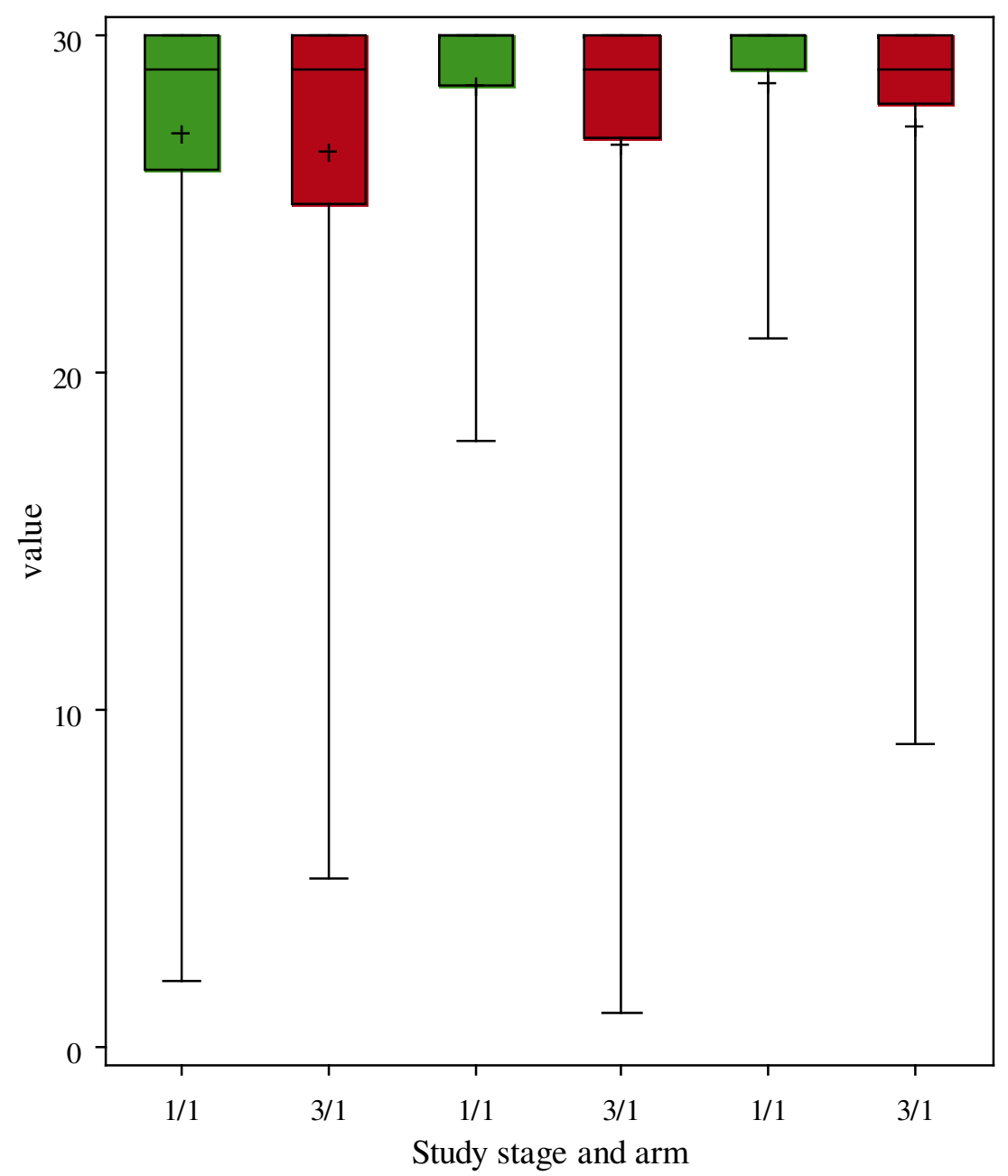


Quantile $=$ median

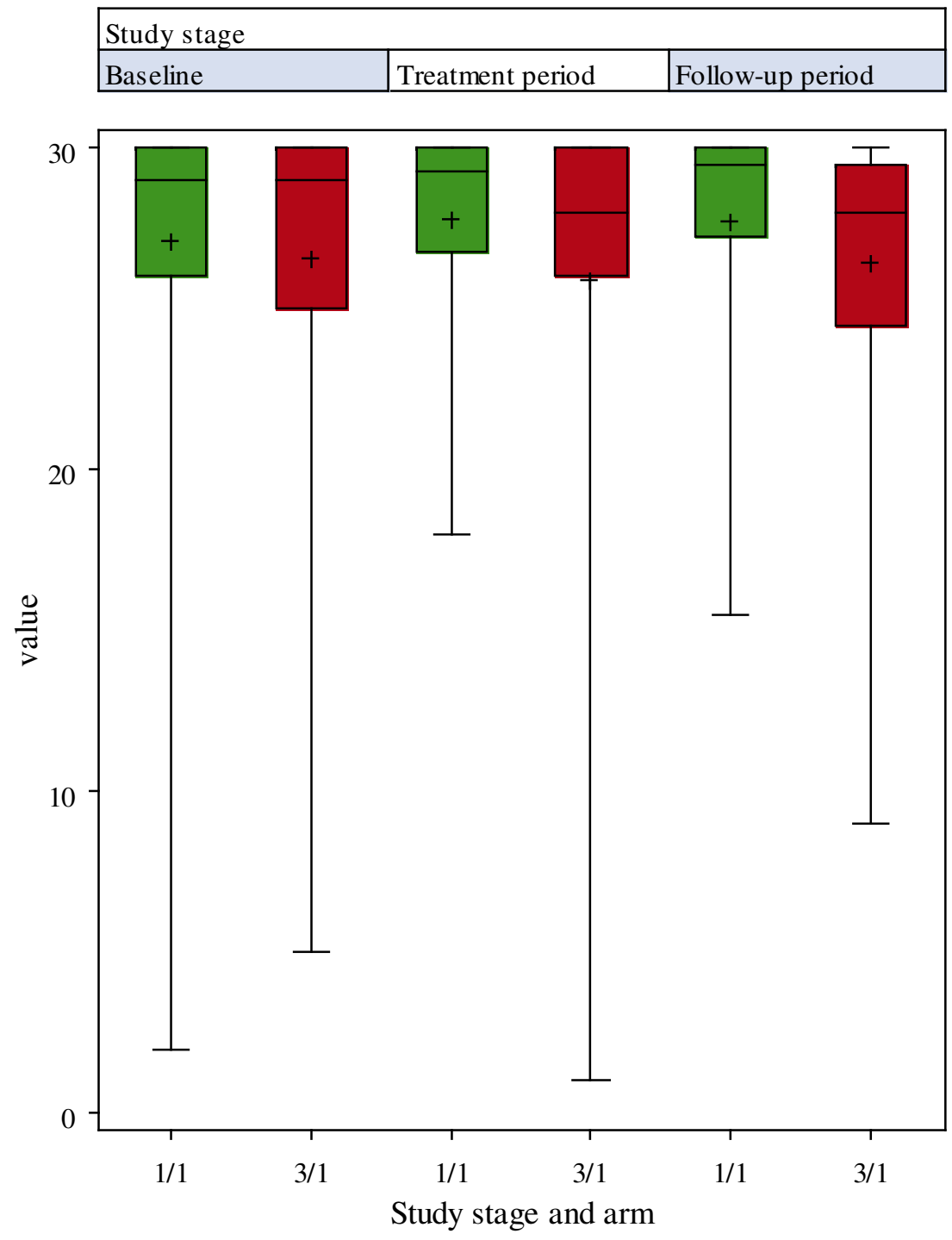


Quantile $=\min$

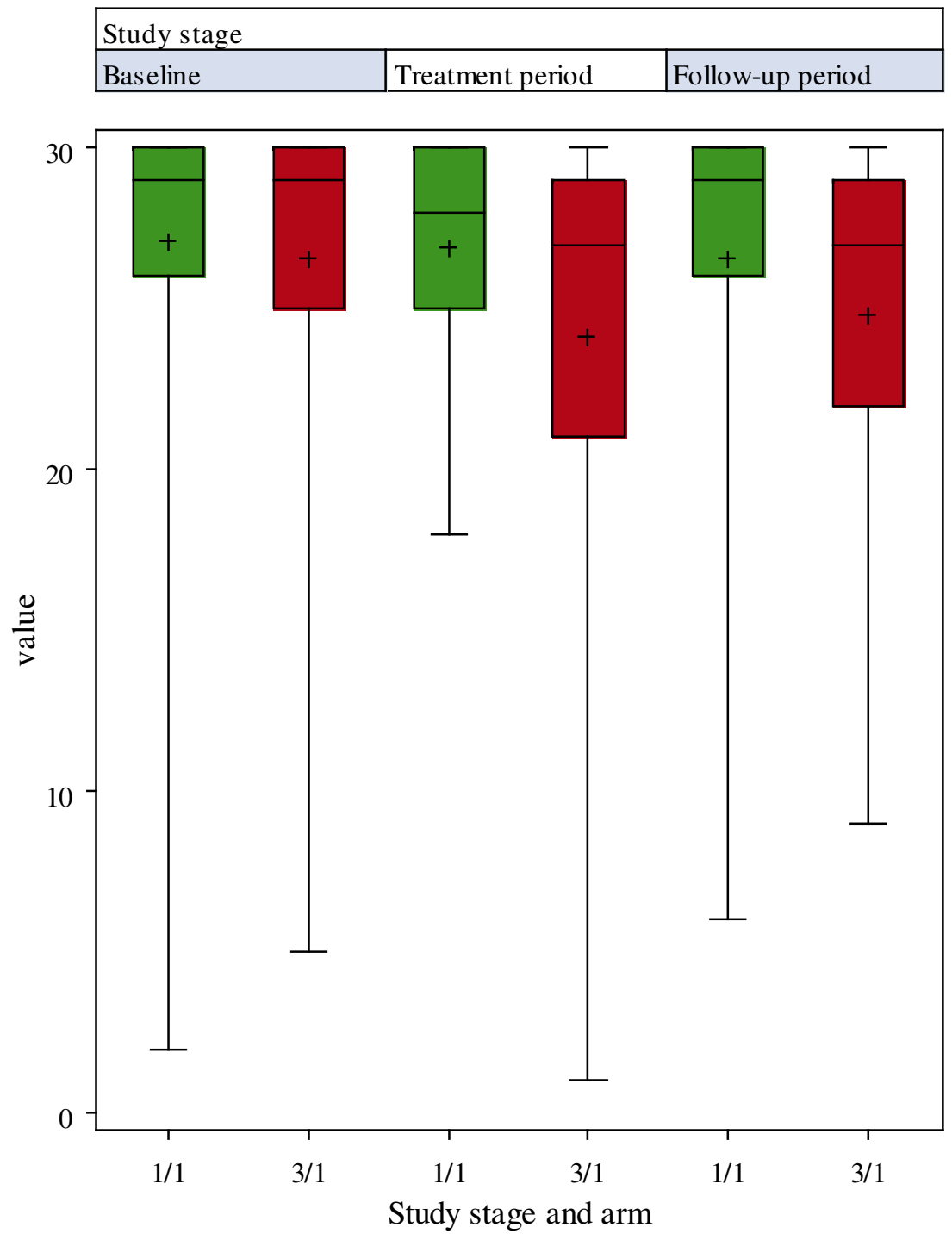


MGMT promoter methylation is a strong prognostic biomarker for benefit from dose-intensified temozolomide rechallenge in progressive glioblastoma: the DIRECTOR trial

Michael Weller ${ }^{1+}$, Ghazaleh Tabatabai ${ }^{1+}$, Bärbel Kästner ${ }^{2}$, Jörg Felsberg ${ }^{3}$, Joachim P. Steinbach ${ }^{4}$, Antje Wick ${ }^{5}$, Oliver Schnell ${ }^{6}$, Peter $\mathrm{Hau}^{7}$, Ulrich Herrlinger ${ }^{8}$, Michael C. Sabel $^{9}$, Hans-Georg Wirsching ${ }^{1}$, Ralf Ketter ${ }^{10}$, Oliver Bähr ${ }^{4}$, Michael Platten ${ }^{5}$, Jörg C. Tonn $^{6}$, Uwe Schlegel ${ }^{11}$, Christine Marosi ${ }^{12}$, Roland Goldbrunner ${ }^{13}$, Roger Stupp ${ }^{14}$, Krisztian Homicsko $^{14}$, Josef Pichler ${ }^{15}$, Guido Nikkhah ${ }^{16}$, Jürgen Meixensberger ${ }^{17}$, Peter Vajkoczy ${ }^{18}$, Spyros Kollias ${ }^{19}$, Johannes Hüsing ${ }^{2}$, Guido Reifenberger ${ }^{3 \#}$, Wolfgang Wick ${ }^{5 \#}$, for the DIRECTOR Study Group

Departments of ${ }^{1}$ Neurology and ${ }^{19}$ Neuroradiology, University Hospital Zurich, Zurich, Switzerland; ${ }^{2}$ Clinical Trial Center Heidelberg, University Hospital Heidelberg, Heidelberg, Germany; ${ }^{3}$ Department of Neuropathology, Heinrich Heine University Düsseldorf, German Cancer Consortium (DKTK), German Cancer Research Center (DKFZ), Heidelberg, Germany; ${ }^{4}$ Dr. Senckenberg Institute for Neuro-Oncology, University Hospital Frankfurt, Frankfurt, Germany; ${ }^{5}$ Department of Neurology, Heidelberg University Medical Center; National Center for Tumor Diseases Heidelberg, German Cancer Consortium (DKTK), German Cancer Research Center (DKFZ), Heidelberg, Germany; ${ }^{6}$ Department of Neurosurgery, Ludwig Maximilian University of Munich, Munich, Germany, ${ }^{7}$ Department of Neurology and Wilhelm Sander-NeuroOncology Unit, University Hospital Regensburg, Regensburg, Germany; ${ }^{8}$ Division of Clinical Neuro-Oncology, Department of Neurology, University of Bonn Medical Center, Bonn, Germany; ${ }^{9}$ Department of Neurosurgery, Heinrich Heine University Düsseldorf, Düsseldorf, Germany; ${ }^{10}$ Department of Neurosurgery, 
Saarland University, Homburg, Germany; ${ }^{11}$ Department of Neurology, University Hospital Bochum, Bochum, Germany; ${ }^{12}$ Department of Oncology, Medical University Vienna, Vienna, Austria; ${ }^{13}$ Department of Neurosurgery, University Hospital Cologne, Cologne, Germany; ${ }^{14}$ Department of Neurosciences, Centre Hospitalier Universitaire Vaudois, Lausanne, Switzerland; ${ }^{15}$ Department of Oncology, Hospital Linz, Austria, ${ }^{16}$ Department of Neurosurgery, University Hospital Freiburg, Germany; ${ }^{17}$ Department of Neurosurgery, University Hospital Leipzig, Germany ${ }^{18}$ Department of Neurosurgery, University Hospital Berlin Charité, Germany

${ }^{+} \mathrm{MW}$ and GT share first authorship, "GR and WW share senior authorship.

\section{Running head}

DIRECTOR trial for recurrent glioblastoma 


\section{Supplementary Tables}

\section{Supplementary Table 1. Safety and tolerability.}

\begin{tabular}{|c|c|c|c|c|c|c|}
\hline \multirow[b]{2}{*}{ CTCAE grade } & \multicolumn{3}{|c|}{$\begin{array}{l}\text { Arm A } \\
n=52\end{array}$} & \multicolumn{3}{|c|}{$\begin{array}{l}\text { Arm B } \\
n=52^{*}\end{array}$} \\
\hline & 2 & 3 & 4 & 2 & 3 & 4 \\
\hline \multicolumn{7}{|l|}{ Hematological toxicity $^{1}, \mathrm{n}$} \\
\hline Neutropenia & 0 & 1 & 0 & 0 & 1 & 0 \\
\hline Lymphopenia & 3 & 8 & 2 & 2 & 14 & 1 \\
\hline Thrombocytopenia & 1 & 1 & 1 & 1 & 2 & 0 \\
\hline $\begin{array}{l}\text { Liver enzyme elevation }(\gamma-G T) \text {, } \\
n\end{array}$ & 0 & 0 & 1 & 1 & 0 & 0 \\
\hline All infections ${ }^{2}, n$ & 5 & 5 & 0 & 5 & 4 & 0 \\
\hline Thrombembolic event, $\mathrm{n}$ & 4 & 2 & 0 & 1 & 0 & 0 \\
\hline Fatigue, $\mathrm{n}$ & 4 & 0 & 0 & 4 & 1 & 0 \\
\hline Nausea / Vomiting ${ }^{3}, \mathrm{n}$ & 6 & 0 & 0 & 4 & 0 & 0 \\
\hline Seizures, $\mathrm{n}$ & 5 & 1 & 0 & 10 & 4 & 0 \\
\hline $\begin{array}{l}\text { Cutaneous adverse events } \\
\text { (dermatitis, allergic rash, } \\
\text { alopecia), n }\end{array}$ & 3 & 0 & 0 & 1 & 0 & 0 \\
\hline
\end{tabular}

*1 patient in Arm B did not receive any study drug.

${ }^{1}$ The criteria were solely based on hematological toxicities that were observed while the patients were on treatment. To continue TMZ after a drug-free week, the following conditions had to be met: Absolute neutrophil count [counts/ $\mu$ l] $\left(\right.$ ANC) $\geq 1.5 \times 10^{3}$, Lymphocytes

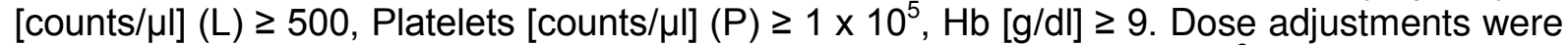
performed in dose levels. A dose level was defined as a step of $30 \mathrm{mg} / \mathrm{m}^{2}$ in Arm A and as a step of $20 \mathrm{mg} / \mathrm{m}^{2}$ in Arm B. Patients in Arm A started with a initial dose of $120 \mathrm{mg} / \mathrm{m}^{2}$. Patients in Arm B started with an initial dose of $80 \mathrm{mg} / \mathrm{m}^{2}$. If the following conditions were met throughout the first cycle, the dose was escalated in each arm as follows: ANC $\geq 2 \times 10^{3}$, $L \geq 800, P \geq 1 \times 10^{5}, \mathrm{Hb} \geq 11$ [g/dl]; Dosage for second cycle Arm A: $150 \mathrm{mg} / \mathrm{m}^{2}$, Arm B: 100 $\mathrm{mg} / \mathrm{m}^{2}$. Further dose escalations beyond $150 \mathrm{mg} / \mathrm{m}^{2}$ in Arm $A$ and beyond $100 \mathrm{mg} / \mathrm{m}^{2}$ in Arm $B$ were not allowed. TMZ administration should be interrupted if any of the following toxicities occured during a treatment week: ANC $<1.0 \times 10^{3}, \mathrm{~L} \geq 250, \mathrm{P}<5 \times 10^{4}$. TMZ administration should also be interrupted if non-haematological toxicities of CTC grade IV occur or if nonhaematological toxicities of CTC grade III persist longer than 14 days. The occurrence of two of the following toxicities in line I or one the following toxicities in line II either in a treatment week or in a drug-free week necessitated a dose reduction in the following cycle: Line I (Reduction of dose levels -1) $1.0 \times 10^{3}<$ ANC $<1.5 \times 10^{3}, 400<\mathrm{L}<500$, P $4 \times 10^{4}<\mathrm{P}<8 \times$ $10^{4}$; Line II (Reduction of dose levels -2) $0.5 \times 10^{3}<\mathrm{ANC}<1.0 \times 10^{3}, 250<\mathrm{L}<400,1 \times 10^{4}<$ 
$P<4 \times 10^{4}$. Treatment could be withheld up to 8 weeks after the last intake of TMZ. Interruption for more than 8 weeks due to hematologic toxicity was defined as treatment failure because of hematological toxicity, leading to withdrawal of the patient from study treatment.

${ }^{2}$ If toxicities occurred (as outlined above), prophylactic treatment with aciclovir as well as trimethoprim and sulfamethoxazol should be started depending on the lymphocyte counts and concomitant steroid medication: Lymphocytes [counts/ $\mu \mathrm{l}$ ] $(\mathrm{L}) \leq 500 / \mu \mathrm{l}$, concomitant steroid medication: Aciclovir 5mg/kg t.i.d., Sulfamethoxazol $800 \mathrm{mg} \&$ Trimethoprim $160 \mathrm{mg}$ b.i.d. once a week; $L \leq 500 / \mu$ l, no concomitant steroid medication: Sulfamethoxazol $800 \mathrm{mg}$ \& Trimethoprim $160 \mathrm{mg}$ b.i.d. once a week; L > 500/ $\mu$, concomitant steroid medication:

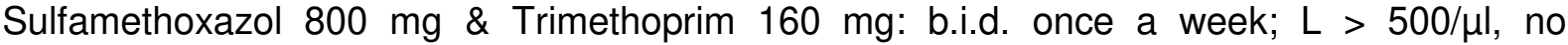
concomitant steroid medication: Optional.

${ }^{3}$ Antiemetics were applied to prevent nausea and vomiting during study treatment. The following drugs were recommended: ondansetron $4 \mathrm{mg}$, tropisetron $5 \mathrm{mg}, 20$ drops metoclopramide, domperidon $10 \mathrm{mg}$. 


\section{Supplementary Table 2. Outcome by MGMT promoter methylation status and treatment arm.}

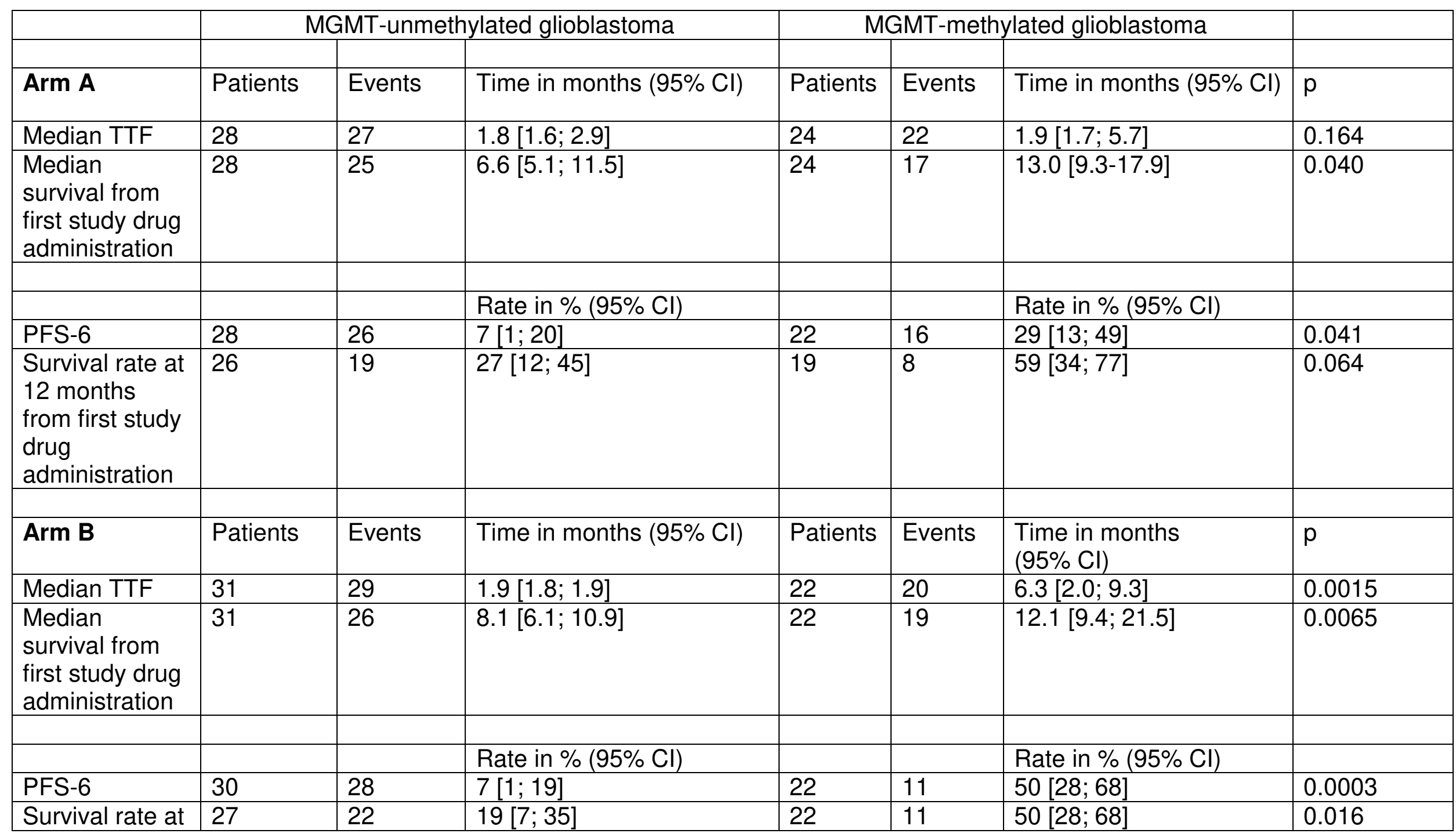




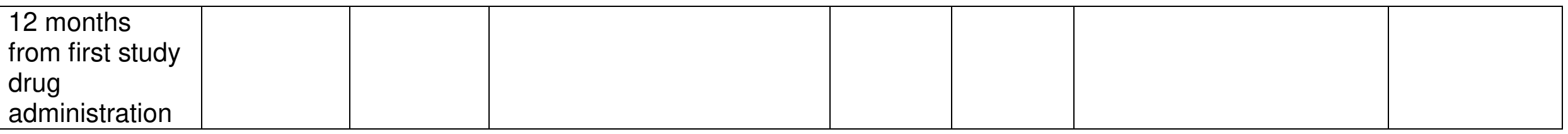

Abbreviations: $\mathrm{Cl}$, confidence interval; PFS, progression-free survival; TTF, time to treatment failure. 


\section{Supplementary Table 3. Outcome by interval from last TMZ administration and MGMT promoter methylation status.}

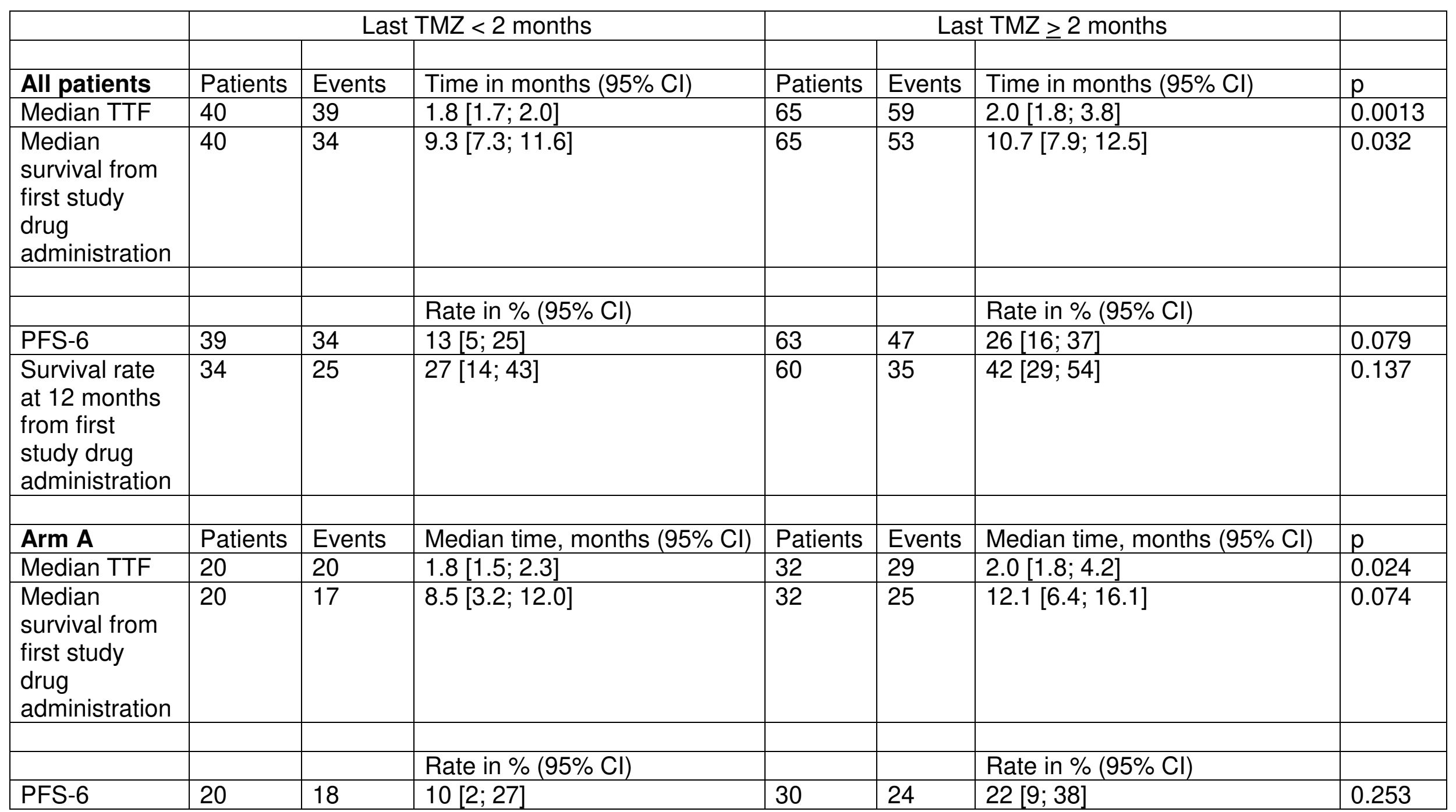




\begin{tabular}{|c|c|c|c|c|c|c|c|}
\hline $\begin{array}{l}\text { Survival rate } \\
\text { at } 12 \text { months } \\
\text { from first } \\
\text { study drug } \\
\text { administration }\end{array}$ & 17 & 13 & $25[8 ; 46]$ & 28 & 14 & $50[31 ; 67]$ & 0.069 \\
\hline Arm B & Patients & Events & Median time, months $(95 \% \mathrm{Cl})$ & Patients & Events & Median time, months $(95 \% \mathrm{Cl})$ & $\mathrm{p}$ \\
\hline Median TTF & 20 & 19 & $1.9[1.8 ; 2.6]$ & 33 & 30 & $2.0[1.8 ; 5.5]$ & 0.04 \\
\hline & & & Rate in \% $(95 \% \mathrm{Cl})$ & & & Rate in \% $(95 \% \mathrm{Cl})$ & \\
\hline PFS-6 & 19 & 16 & $16[4 ; 35]$ & 33 & 23 & $30[16 ; 46]$ & 0.21 \\
\hline & \multicolumn{3}{|c|}{ Last $\mathrm{TMZ}<2$ months } & \multicolumn{3}{|c|}{ Last TMZ $\geq 2$ months } & \\
\hline $\begin{array}{l}\text { MGMT } \\
\text { promoter } \\
\text { unmethylated }\end{array}$ & Patients & Events & Time in months $(95 \% \mathrm{Cl})$ & Patients & Events & Time in months $(95 \% \mathrm{Cl})$ & $p$ \\
\hline Median TTF & 29 & 28 & $1.9(1.8 ; 2.0)$ & 30 & 28 & $1.8(1.8 ; 3.7)$ & 0.30 \\
\hline $\begin{array}{l}\text { Median } \\
\text { survival from } \\
\text { first study }\end{array}$ & 29 & 25 & $8.5[5.7 ; 12.0]$ & 30 & 26 & $6.9[5.6 ; 10.3]$ & 0.76 \\
\hline
\end{tabular}




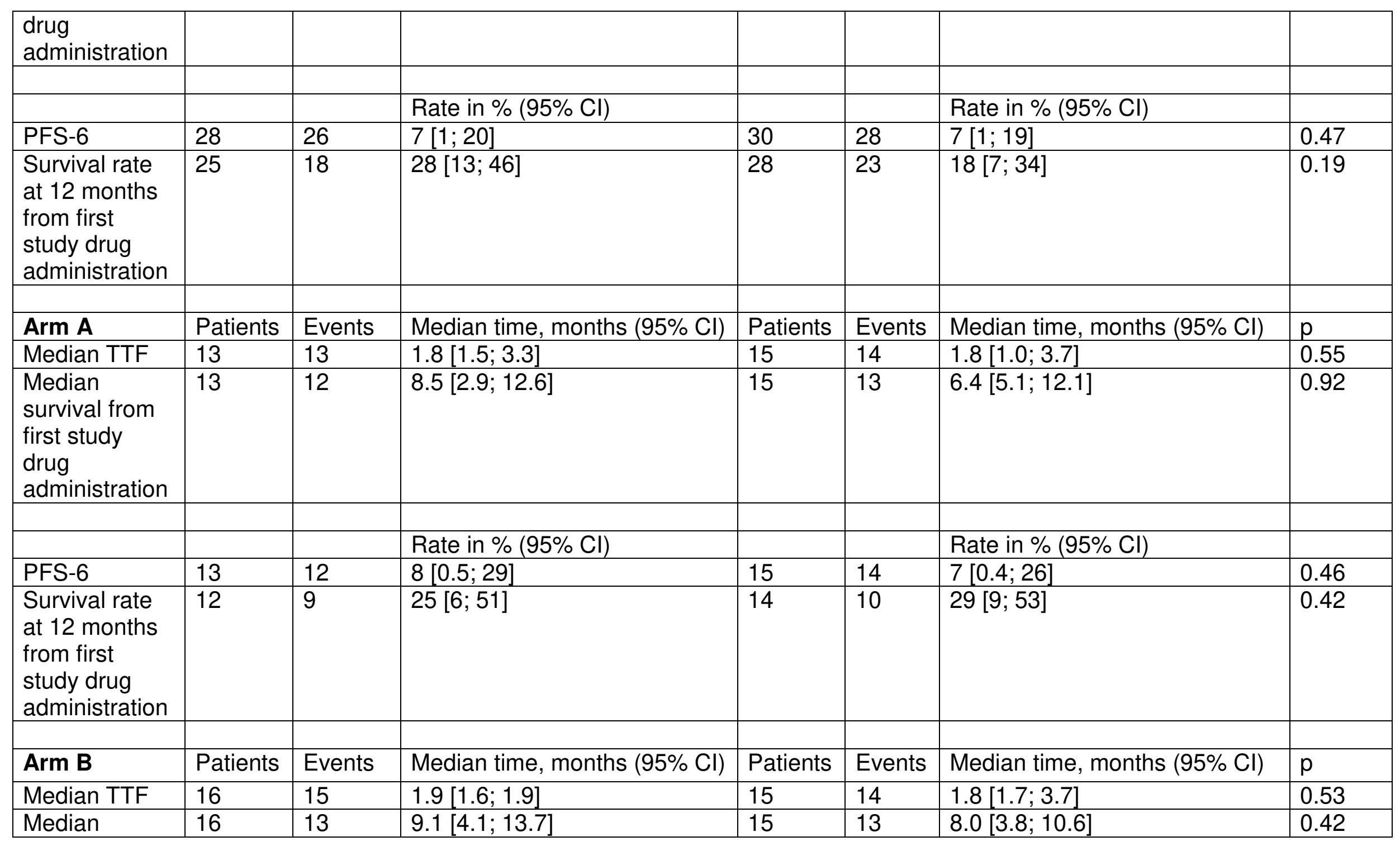




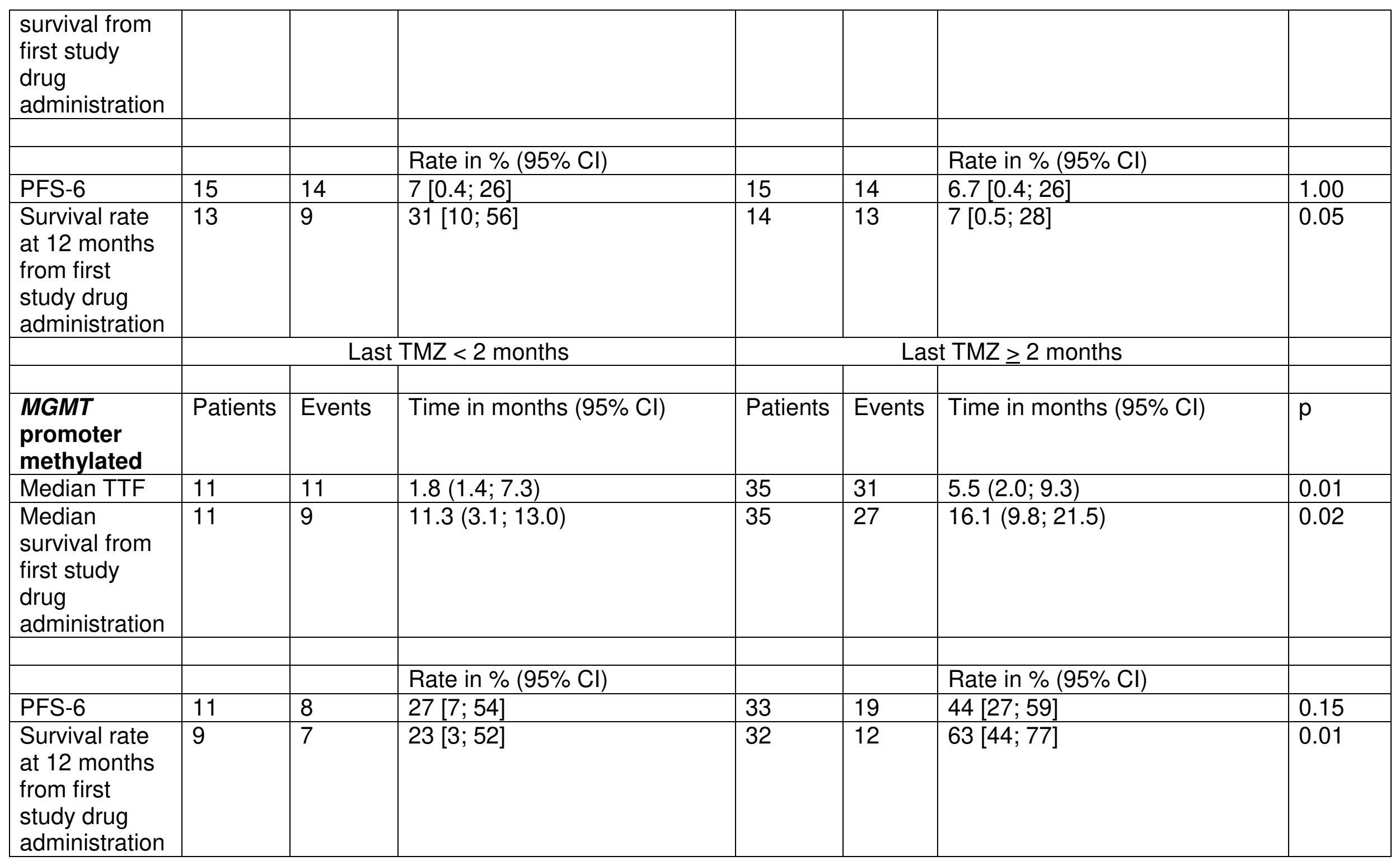




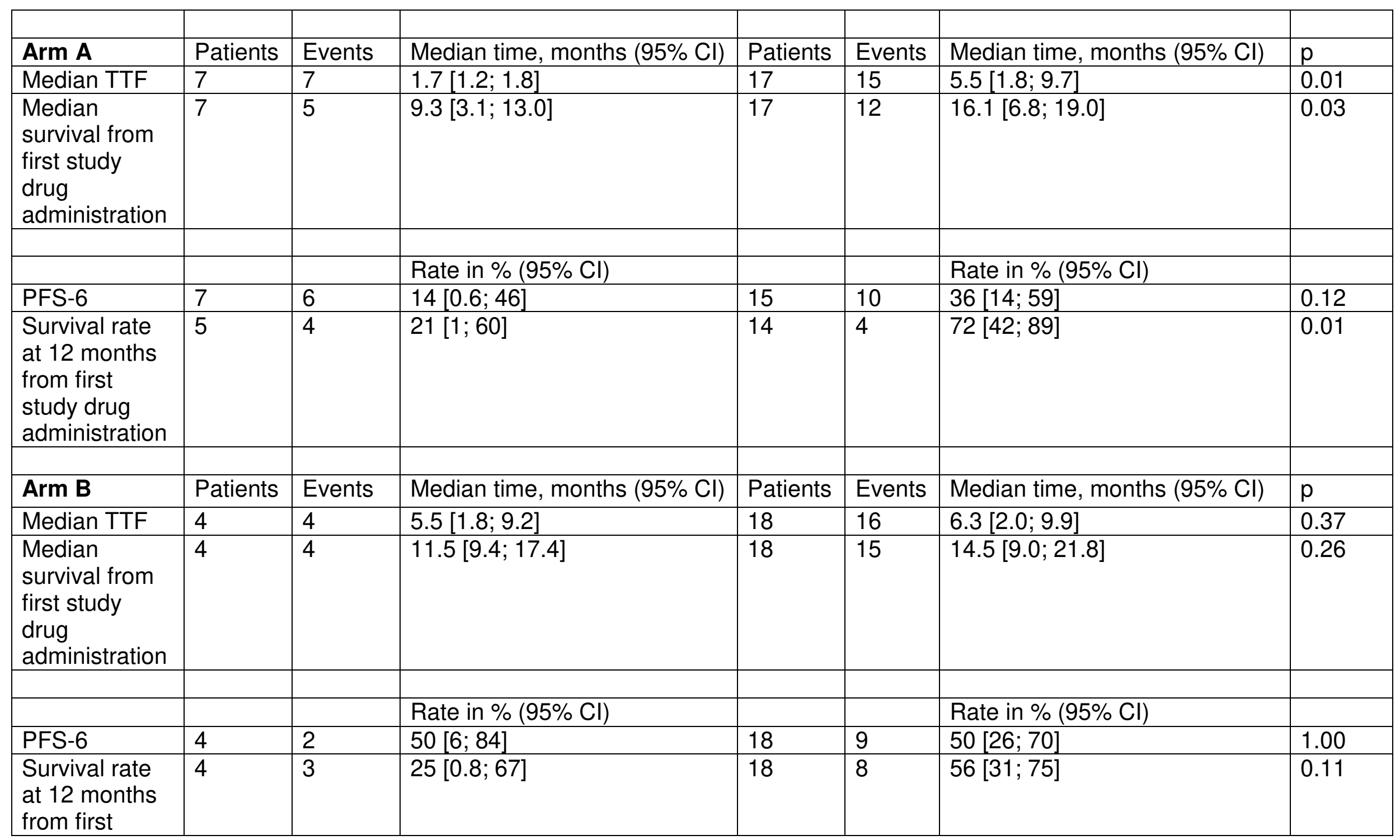




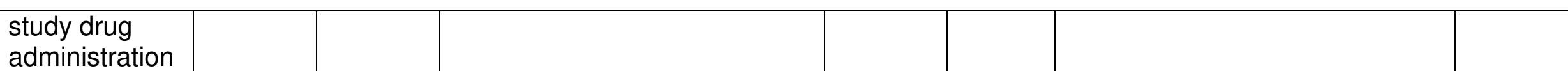

Abbreviations: $\mathrm{Cl}$, confidence interval; PFS, progression-free survival; TMZ, temozolomide; TTF, time to treatment failure. 
Supplementary Table 4. Adherence to Mini Mental Status data collection over the course of the study. ${ }^{1}$

\begin{tabular}{|c|c|c|c|c|c|c|c|c|c|}
\hline \multirow[b]{3}{*}{ Test } & \multirow[b]{3}{*}{ Visit } & \multirow[b]{3}{*}{$\begin{array}{l}\text { Visit } \\
\text { Cycle }\end{array}$} & \multirow{2}{*}{$\begin{array}{l}\text { Visit } \\
\text { done }\end{array}$} & \multicolumn{6}{|c|}{ Patients with test: n / \% } \\
\hline & & & & \multicolumn{2}{|c|}{ DONE } & \multicolumn{2}{|c|}{ NOT DONE } & \multicolumn{2}{|c|}{ MISSING } \\
\hline & & & & & & & & & \\
\hline \multirow[t]{25}{*}{$\begin{array}{l}\text { Mini Mental } \\
\text { Status }\end{array}$} & $\begin{array}{l}\text { Baseline } \\
\text { visit }\end{array}$ & 1 & 105 & 100 & 95.24 & 5 & 4.76 & . & \\
\hline & \multirow{20}{*}{$\begin{array}{l}\text { Treatment } \\
\text { phase } \\
\text { - Every } 4 \\
\text { weeks }\end{array}$} & 1 & 94 & 85 & 90.43 & 9 & 9.57 & . & . \\
\hline & & 2 & 73 & 60 & 82.19 & 12 & 16.44 & 1 & 1.37 \\
\hline & & 3 & 33 & 29 & 87.88 & 4 & 12.12 & . & . \\
\hline & & 4 & 31 & 30 & 96.77 & 1 & 3.23 & . & . \\
\hline & & 5 & 21 & 21 & 100.00 & . & . & . & . \\
\hline & & 6 & 20 & 18 & 90.00 & 2 & 10.00 & - & . \\
\hline & & 7 & 16 & 16 & 100.00 & . & . & . & . \\
\hline & & 8 & 14 & 13 & 92.86 & 1 & 7.14 & . & . \\
\hline & & 9 & 11 & 11 & 100.00 & . & & r & . \\
\hline & & 10 & 9 & 9 & 100.00 & . & . & . & . \\
\hline & & 11 & 7 & 6 & 85.71 & 1 & 14.29 & . & . \\
\hline & & 12 & 6 & 6 & 100.00 & . & & . & . \\
\hline & & 13 & 2 & 2 & 100.00 & . & $\left.\right|^{\circ}$ & . & . \\
\hline & & 14 & 1 & 1 & 100.00 & . & . & . & . \\
\hline & & 15 & 1 & 1 & 100.00 & . & & $\cdot$ & . \\
\hline & & 16 & 1 & 1 & 100.00 & . & . & . & . \\
\hline & & 17 & 1 & 1 & 100.00 & . & . & . & . \\
\hline & & 18 & 1 & 1 & 100.00 & . & & . & . \\
\hline & & 19 & 1 & 1 & 100.00 & . & . & $\cdot$ & . \\
\hline & & 20 & 1 & 1 & 100.00 & . & . & . & . \\
\hline & $\begin{array}{l}\text { End of study } \\
\text { medication } \\
\text { visit }\end{array}$ & 1 & 102 & 67 & 65.69 & 28 & 27.45 & 7 & 6.86 \\
\hline & \multirow{3}{*}{$\begin{array}{l}\text { Follow-up } \\
\text { visit (after } \\
\text { treatment } \\
\text { failure), }\end{array}$} & 1 & 55 & 31 & 56.36 & 23 & 41.82 & 1 & 1.82 \\
\hline & & 2 & 41 & 27 & 65.85 & 13 & 31.71 & 1 & 2.44 \\
\hline & & 3 & 26 & 20 & 76.92 & 6 & 23.08 & & \\
\hline
\end{tabular}




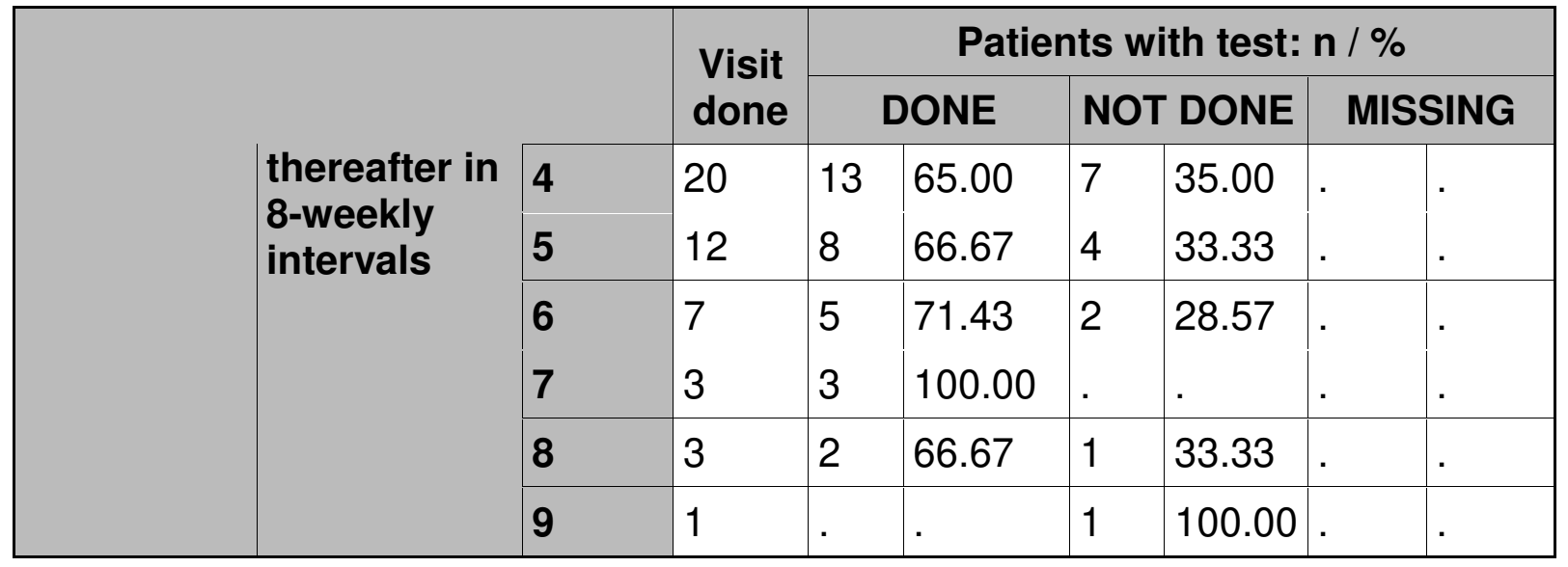


Supplementary Table 5. Treatment effect (Arm B versus Arm A) on EORTCQLQ-C30 and-BN20 scales evaluated at timepoint 90 days ${ }^{1}$.

\begin{tabular}{|c|c|c|c|c|}
\hline Questionnaire & Scale & Effect & $95 \% \mathrm{Cl}$ & $\mathrm{p}$ value \\
\hline \multirow[t]{14}{*}{ EORTC QLQ-C30 } & Appetite loss & -5.08 & {$[-14.87 ; 4.71]$} & 0.3082 \\
\hline & Cognitive functioning & -1.91 & {$[-12.18 ; 8.36]$} & 0.7142 \\
\hline & Constipation & -0.58 & {$[-11.04 ; 9.89]$} & 0.9135 \\
\hline & Dyspnoea & -1.46 & {$[-10.48 ; 7.56]$} & 0.7501 \\
\hline & Emotional functioning & -4.11 & {$[-12.87 ; 4.65]$} & 0.3568 \\
\hline & Fatigue & -4.55 & {$[-14.21 ; 5.10]$} & 0.3536 \\
\hline & Financial difficulties & -5.82 & {$[-14.82 ; 3.18]$} & 0.2038 \\
\hline & Global health status & 0.02 & {$[-8.38 ; 8.43]$} & 0.9954 \\
\hline & Insomnia & -3.39 & {$[-12.83 ; 6.06]$} & 0.4811 \\
\hline & Nausea and vomiting & 2.47 & {$[-3.99 ; 8.94]$} & 0.4522 \\
\hline & Pain & 4.36 & {$[-5.90 ; 14.62]$} & 0.4036 \\
\hline & Physical functioning & -4.73 & {$[-13.79 ; 4.32]$} & 0.3044 \\
\hline & Role functioning & -1.26 & {$[-13.58 ; 11.05]$} & 0.8400 \\
\hline & Social functioning & -2.16 & {$[-11.55 ; 7.23]$} & 0.6504 \\
\hline \multirow[t]{10}{*}{ EORTC QLQ-BN20 } & Bladder control & 1.72 & {$[-9.96 ; 13.40]$} & 0.7717 \\
\hline & Communication deficit & 1.42 & {$[-9.70 ; 12.55]$} & 0.8014 \\
\hline & Drowsiness & -6.79 & {$[-16.17 ; 2.60]$} & 0.1555 \\
\hline & Future uncertainty & -7.24 & {$[-16.72 ; 2.23]$} & 0.1335 \\
\hline & Hair loss & -0.58 & {$[-9.06 ; 7.90]$} & 0.8928 \\
\hline & Headaches & 11.83 & [ $1.48 ; 22.18]$ & 0.0253 \\
\hline & Itchy skin & 0.20 & {$[-8.01 ; 8.40]$} & 0.9626 \\
\hline & Motor dysfunction & -3.37 & {$[-13.81 ; 7.07]$} & 0.5255 \\
\hline & Seizures & 6.04 & {$[-3.15 ; 15.22]$} & 0.1969 \\
\hline & Visual disorder & 5.24 & {$[-1.77 ; 12.24]$} & 0.1423 \\
\hline
\end{tabular}

${ }^{1}$ Estimates of expected values of treatment differences at timepoint 90 days, obtained from a generalized linear mixed model incorporating baseline score, treatment group, days after randomization with time/treatment and time/baseline interactions. 
Supplementary Table 6. Absolute changes of $(0-100)$ score points of quality of life (as assessed by the EORTC-QLQ-C30 and -BN20 scales) within one treatment cycle of 28 days in Arms $A$ and $B$, along with local p-values for difference in slopes. ${ }^{1}$

\begin{tabular}{|c|c|c|c|c|}
\hline Questionnaire & Scale & Arm A & Arm B & $p$ value \\
\hline \multirow{14}{*}{$\begin{array}{l}\text { EORTC QLQ- } \\
\text { C30 }\end{array}$} & Appetite loss & 0.130 & 0.821 & 0.054 \\
\hline & Cognitive functioning & 0.270 & 0.984 & 0.055 \\
\hline & Constipation & -1.02 & -.396 & 0.110 \\
\hline & Dyspnoea & 0.093 & 0.422 & 0.316 \\
\hline & Emotional functioning & 0.149 & 0.731 & 0.040 \\
\hline & Fatigue & 0.124 & 1.118 & 0.005 \\
\hline & Financial difficulties & -.021 & -.201 & 0.586 \\
\hline & Global health status & 0.362 & 0.301 & 0.832 \\
\hline & Insomnia & 0.156 & 0.362 & 0.647 \\
\hline & Nausea and vomiting & 0.006 & -.198 & 0.382 \\
\hline & Pain & -.364 & 0.795 & 0.001 \\
\hline & Physical functioning & 0.310 & 1.142 & 0.007 \\
\hline & Role functioning & 0.321 & 0.830 & 0.159 \\
\hline & Social functioning & 0.660 & 1.167 & 0.119 \\
\hline \multirow{10}{*}{$\begin{array}{l}\text { EORTC QLQ- } \\
\text { BN20 }\end{array}$} & Bladder control & 0.141 & 0.655 & 0.133 \\
\hline & Communication deficit & -.050 & 0.886 & 0.017 \\
\hline & Drowsiness & 0.494 & 1.119 & 0.116 \\
\hline & Future uncertainty & 0.300 & 1.199 & 0.003 \\
\hline & Hair loss & 0.009 & 0.296 & 0.362 \\
\hline & Headaches & -.099 & 0.693 & 0.039 \\
\hline & Itchy skin & 0.147 & -.058 & 0.566 \\
\hline & Motor dysfunction & 0.519 & 0.872 & 0.260 \\
\hline & Seizures & 0.057 & 0.324 & 0.447 \\
\hline & Visual disorder & -.019 & 0.580 & 0.037 \\
\hline
\end{tabular}

${ }^{1}$ Estimates of treatment by time interaction parameters in generalized linear mixed model incorporating baseline score, treatment group, days after randomization with time/treatment and time/baseline interactions. 
Supplementary Table 7. Adherence to EORTC-QLQ-BN20 and -C30 data collection over the course of the study. ${ }^{1}$

\begin{tabular}{|c|c|c|c|c|c|c|c|c|c|}
\hline \multirow[b]{3}{*}{ Test } & \multirow[b]{3}{*}{ Visit } & \multirow[b]{3}{*}{$\begin{array}{l}\text { Visit } \\
\text { Cycle }\end{array}$} & \multirow{4}{*}{$\begin{array}{l}\text { Visit } \\
\text { done }\end{array}$} & \multicolumn{6}{|c|}{ Patients with test: $\mathbf{n} / \%$} \\
\hline & & & & \multicolumn{2}{|c|}{ DONE } & \multicolumn{2}{|c|}{$\begin{array}{c}\text { NOT } \\
\text { DONE }\end{array}$} & \multicolumn{2}{|c|}{ MISSINC } \\
\hline & & & & 101 & 96.19 & 3 & 2.86 & 1 & 0.95 \\
\hline \multirow[t]{21}{*}{$\begin{array}{l}\text { EORTC QLQ- } \\
\text { C30/-BN20 }\end{array}$} & $\begin{array}{l}\text { Baseline } \\
\text { visit }\end{array}$ & 1 & & & & & & & \\
\hline & \multirow{10}{*}{$\begin{array}{l}\text { Treatment } \\
\text { phase - } \\
\text { every } 8 \\
\text { weeks }\end{array}$} & 1 & 86 & 75 & 87.21 & 7 & 8.14 & 4 & 4.65 \\
\hline & & 2 & 38 & 34 & 89.47 & 2 & 5.26 & 2 & 5.26 \\
\hline & & 3 & 23 & 21 & 91.30 & 1 & 4.35 & 1 & 4.35 \\
\hline & & 4 & 14 & 14 & 100.00 & & . & . & . \\
\hline & & 5 & 11 & 11 & 100.00 & & . & . & . \\
\hline & & 6 & 6 & 6 & 100.00 & & . & . & . \\
\hline & & 7 & 1 & 1 & 100.00 & & . & 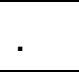 & . \\
\hline & & 8 & 1 & 1 & 100.00 & & . & & . \\
\hline & & 9 & 1 & 1 & 100.00 & & . & & . \\
\hline & & 10 & 1 & 1 & 100.00 & & . & & . \\
\hline & \begin{tabular}{|l|} 
End of \\
study \\
medication \\
visit \\
\end{tabular} & 1 & 102 & 66 & 64.71 & 26 & 25.49 & 10 & 9.80 \\
\hline & \multirow{9}{*}{$\begin{array}{l}\text { Follow-up } \\
\text { visit (after } \\
\text { treatment } \\
\text { failure), } \\
\text { thereafter } \\
\text { in 8-weekly } \\
\text { intervals }\end{array}$} & 1 & 55 & 36 & 65.45 & 18 & 32.73 & 1 & 1.82 \\
\hline & & 2 & 41 & 30 & 73.17 & 11 & 26.83 & & . \\
\hline & & 3 & 26 & 21 & 80.77 & 5 & 19.23 & &. \\
\hline & & 4 & 20 & 17 & 85.00 & 3 & 15.00 & & . \\
\hline & & 5 & 12 & 9 & 75.00 & 3 & 25.00 & . & . \\
\hline & & 6 & 7 & 5 & 71.43 & 2 & 28.57 & . & . \\
\hline & & 7 & 3 & 3 & 100.00 & . & . & . & . \\
\hline & & 8 & 3 & 3 & 100.00 & & . & & . \\
\hline & & 9 & 1 & 1 & 100.00 & & . & . & . \\
\hline
\end{tabular}


Figure 2

A

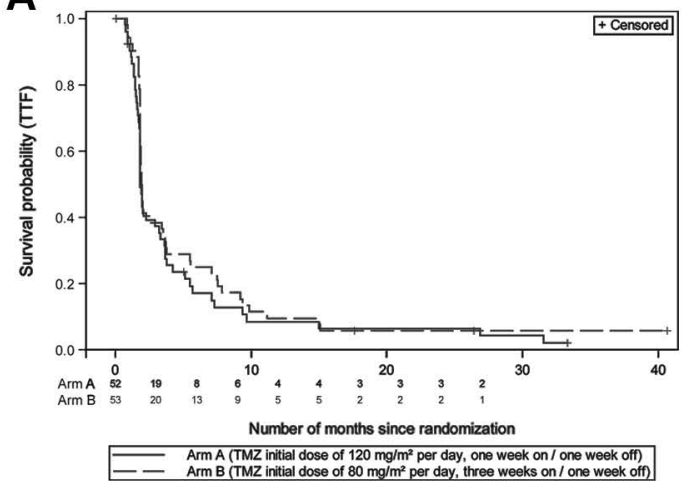

C

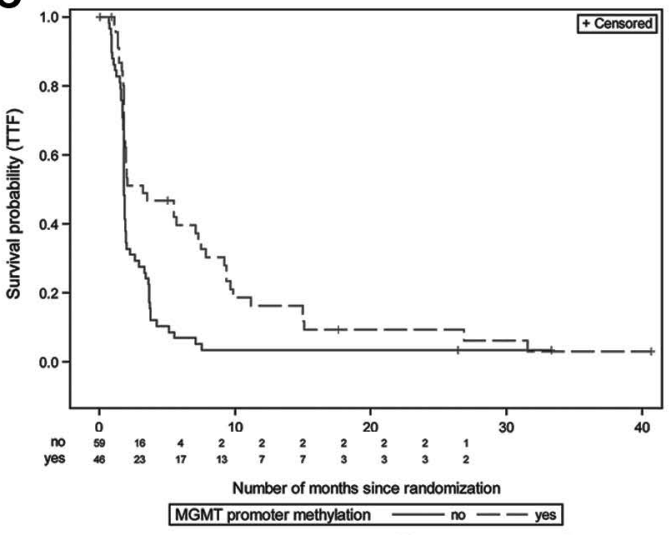

B

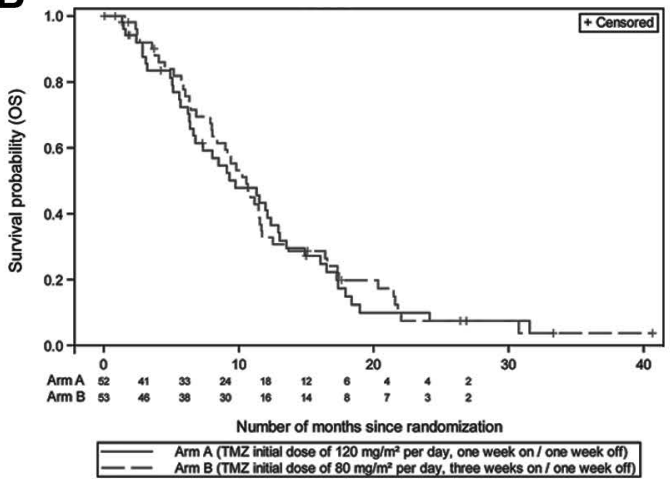

D

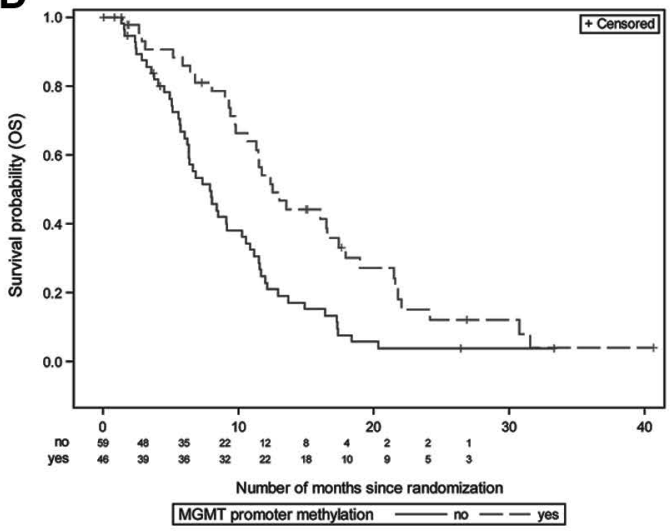


